\title{
Secondary aerosol formation from atmospheric reactions of aliphatic amines
}

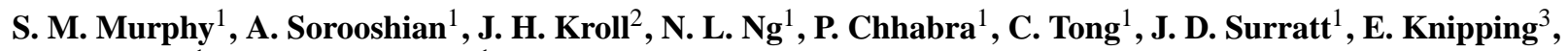 \\ R. C. Flagan ${ }^{1}$, and J. H. Seinfeld ${ }^{1}$ \\ ${ }^{1}$ Division of Chemistry and Chemical Engineering, California Institute of Technology, Pasadena, CA 91125, USA \\ ${ }^{2}$ Current Address: Aerodyne Research Inc., Billerica, MA, USA \\ ${ }^{3}$ Electric Power Research Institute, Palo Alto, CA, USA
}

Received: 17 December 2006 - Published in Atmos. Chem. Phys. Discuss.: 10 January 2007

Revised: 13 April 2007 - Accepted: 13 April 2007 - Published: 8 May 2007

\begin{abstract}
Although aliphatic amines have been detected in both urban and rural atmospheric aerosols, little is known about the chemistry leading to particle formation or the potential aerosol yields from reactions of gas-phase amines. We present here the first systematic study of aerosol formation from the atmospheric reactions of amines. Based on laboratory chamber experiments and theoretical calculations, we evaluate aerosol formation from reaction of $\mathrm{OH}$, ozone, and nitric acid with trimethylamine, methylamine, triethylamine, diethylamine, ethylamine, and ethanolamine. Entropies of formation for alkylammonium nitrate salts are estimated by molecular dynamics calculations enabling us to estimate equilibrium constants for the reactions of amines with nitric acid. Though subject to significant uncertainty, the calculated dissociation equilibrium constant for diethylammonium nitrate is found to be sufficiently small to allow for its atmospheric formation, even in the presence of ammonia which competes for available nitric acid. Experimental chamber studies indicate that the dissociation equilibrium constant for triethylammonium nitrate is of the same order of magnitude as that for ammonium nitrate. All amines studied form aerosol when photooxidized in the presence of $\mathrm{NO}_{\mathrm{x}}$ with the majority of the aerosol mass present at the peak of aerosol growth consisting of aminium $\left(\mathrm{R}_{3} \mathrm{NH}^{+}\right)$nitrate salts, which repartition back to the gas phase as the parent amine is consumed. Only the two tertiary amines studied, trimethylamine and triethylamine, are found to form significant nonsalt organic aerosol when oxidized by $\mathrm{OH}$ or ozone; calculated organic mass yields for the experiments conducted are similar for ozonolysis (15\% and 5\% respectively) and photooxidation (23\% and $8 \%$ respectively). The non-salt organic aerosol formed appears to be more stable than the nitrate salts and does not quickly repartition back to the gas phase.
\end{abstract}

Correspondence to: J. H. Seinfeld

(seinfeld@ caltech.edu)

\section{Introduction}

Amines are emitted into the atmosphere from a variety of sources including meat cooking, biomass burning, motor vehicle exhaust, industrial processes, and marine organisms. The dominant anthropogenic source is emissions from animal husbandry operations (Table 1). While amine emissions from animal husbandry are typically reported to be two to three orders of magnitude less than those of ammonia (Ngwabie and Hintz, 2005; Schade and Crutzen, 1995), at least one study has reported gas-phase concentrations of amines in the hundreds of ppb in areas of intense animal husbandry (Rabaud et al., 2003). Though emission estimates vary widely, amines have been detected in marine, rural, and urban atmospheres in the gas phase, particle phase and within aqueous fog and rain drops (Zhang and Anastasio, 2003). Mass spectrometric studies by both Murphy (1997) and Angelino (2001) have shown that molecular ions typically associated with amines are present in ambient particles, especially in air masses from agricultural regions. Tan et al. (2002) identified particle phase amines during multiple smog events in Toronto's winter atmosphere. Recent field studies suggest that organic nitrogen species could be an appreciable fraction of organic aerosol mass (Beddows et al., 2004; Mace et al., 2003; Makela et al., 2001; McGregor and Anastasio, 2001; Neff et al., 2002; Simoneit et al., 2003; Tan et al., 2002), although the relative importance of amines as a source of particulate organic nitrogen remains unclear.

During the 1970's, interest in the gas-phase atmospheric chemistry of amines focused on carcinogenic nitrosamines formed when amines are photooxidized (Pitts et al., 1978). It was subsequently determined that gas-phase nitrosamines photolyze rapidly in the troposphere and are believed to pose a minimal threat to human health. More recently, toxicology studies have demonstrated that particulate organic nitrogen species are associated with adverse health effects (Hamoir et

Published by Copernicus Publications on behalf of the European Geosciences Union. 
Table 1. Summary of structures of amines studied and estimated global emissions from animal husbandry.

\begin{tabular}{lcc}
\hline Amine (abbrev) & Formula & $\begin{array}{c}\text { Estimated Global Emissions, Gg N y } \\
\text { (Schade and Crutzen, 1995) }\end{array}$ \\
\hline Ammonia & $\mathrm{NH}_{3}$ & 23300 \\
Methylamine (MA) & $\mathrm{CH}_{3} \mathrm{NH}_{2}$ & $24 \pm 15$ \\
Trimethylamine (TMA) & $\left(\mathrm{CH}_{3}\right)_{3} \mathrm{~N}$ & $108 \pm 30$ \\
Diethylamine (DEA) & $\left(\mathrm{CH}_{3} \mathrm{CH}_{2}\right)_{2} \mathrm{NH}$ & - \\
Triethylamine (TEA) & $\left(\mathrm{CH}_{3} \mathrm{CH}_{2}\right)_{3} \mathrm{~N}$ & - \\
Ethanolamine (MEA) & $\left(\mathrm{CH}_{2} \mathrm{OH}\right) \mathrm{CH}_{2} \mathrm{NH}_{2}$ & - \\
\hline
\end{tabular}

al., 2003). Nemmar (2002) found that particles coated with amines produced a significant increase in the rate of blood clots (by nearly 4 times) when installed in the trachea of hamsters; in contrast, the effects of particles coated with carboxylic acids and unmodified polystyrene particles were not statistically significant when compared to the control group of hamsters.

Amines are oxidized in the atmosphere by the hydroxyl radical $(\mathrm{OH})$, ozone $\left(\mathrm{O}_{3}\right)$, and possibly by the nitrate radical $\left(\mathrm{NO}_{3}\right)$, with measured rate constants suggesting that the reaction rates of ozone and $\mathrm{OH}$ with amines are competitive during the day if ozone levels are in the tens to hundreds of ppb (Tuazon et al., 1994). The nitrate radical may play a significant role in amine oxidation at night, though very little is known about this pathway. While many of the gas-phase oxidation pathways involving $\mathrm{OH}$ and ozone have been elucidated, secondary aerosol formation resulting from the photooxidation of amines has received limited attention. Also, because amines are basic compounds, they can form particulate salts through reactions with gas-phase acids present in the atmosphere $\left(\mathrm{HNO}_{3}, \mathrm{H}_{2} \mathrm{SO}_{4}\right)$,

$\mathrm{NR}_{3}(\mathrm{~g})+\mathrm{HNO}_{3}(\mathrm{~g}) \rightleftarrows \mathrm{HNR}_{3} \mathrm{NO}_{3}(\mathrm{~s})$

$2 \mathrm{NR}_{3}(\mathrm{~g})+\mathrm{H}_{2} \mathrm{SO}_{4}(\mathrm{~g}) \rightleftarrows\left(\mathrm{HNR}_{3}\right)_{2} \mathrm{SO}_{4}(\mathrm{~s})$

Reactions (R1) and (R2) are analogous to those of ammonia to form ammonium sulfate and ammonium nitrate. While the equilibria between gas-phase ammonia and nitric or sulfuric acid to form particle-phase salts have been thoroughly investigated and the thermodynamic parameters governing these reactions are well known (Mozurkewich, 1993; Stelson and Seinfeld, 1982), similar thermodynamic parameters for amine systems were not available prior to this study.

There have been a limited number of laboratory chamber experiments in which aerosol resulting from amine photooxidation was observed (Angelino et al., 2001; Pitts et al., 1978). Aerosol yields, the relative importance of acid-base chemistry, and the oxidative pathways leading to particle formation remain poorly understood. The goal of the present work is to use controlled laboratory chamber studies to evaluate the aerosol forming potential, by acid-base reactions, photooxidation and ozonolysis, of aliphatic amines known to be present in the atmosphere. The amines studied (with abbreviation used) are: trimethylamine (TMA), methylamine (MA), triethylamine (TEA), diethylamine (DEA), ethylamine (EA), and monoethanolamine (MEA), which will be referred to as ethanolamine in this paper.

\section{Experimental}

All experiments (Table 2) were carried out in the Caltech dual $28 \mathrm{~m}^{3}$ FEP Teflon chambers (Cocker et al., 2001; Keywood et al., 2004). The chambers are surrounded by banks of black lights (276GE350BL) which output ultraviolet light predominantly between 300 and $400 \mathrm{~nm}$, with a maximum at $354 \mathrm{~nm}$. Ports allow for the introduction of clean, dry $(<10 \%$ $\mathrm{RH})$ air, gas-phase reagents, inorganic seed aerosol, and for measurement of $\mathrm{NO}, \mathrm{NO}_{\mathrm{x}}, \mathrm{O}_{3}, \mathrm{RH}$, temperature, and particulate mass, size, number concentration, and chemistry. Temperature is held at $20^{\circ} \mathrm{C}$, increasing to $25^{\circ} \mathrm{C}$ during photooxidation experiments using the black lights. Commercial monitors (Horiba) are used to measure $\mathrm{O}_{3}$ (by UV absorption) and $\mathrm{NO} / \mathrm{NO}_{\mathrm{x}}\left(\mathrm{NO}_{\mathrm{x}}\right.$ conversion to $\mathrm{NO}$ by activated carbon, followed by $\mathrm{NO}+\mathrm{O}_{3}$ chemiluminescence). Both amines and nitric acid (when added) were injected into the chamber by passing a stream of dry, clean air over a known volume of high purity liquid phase compound. The purity and source of the amines used in this study are: trimethylamine ( $45 \%$ solution in $\mathrm{H}_{2} \mathrm{O}$, Fluka), methylamine (40 wt.\% solution in $\mathrm{H}_{2} \mathrm{O}$, Sigma-Aldrich), triethylamine ( $>99.5 \%$ purity, Sigma Aldrich), diethylamine ( $>99.5 \%$ purity, Sigma Aldrich), ethylamine (70 wt.\% solution in $\mathrm{H}_{2} \mathrm{O}$, Aldrich), ethanolamine, ( $\geq 99 \%$ purity, Sigma Aldrich). Gas-phase concentrations of amines and nitric acid were not directly measured and were instead estimated based on the volume of liquid phase amine injected; these concentrations represent the maximum possible within the chamber in the absence of wall loss.

"Seed" aerosol was generated by atomizing a solution of $0.015 \mathrm{M}$ ammonium sulfate or $0.75 \mathrm{M}$ ammonium nitrate. Particle-phase measurements were made by an Aerodyne Time of Flight Aerosol Mass Spectrometer (cToF-AMS), a Particle-Into-Liquid Sampler coupled to Ion 
Table 2. Initial conditions of all experiments conducted.

\begin{tabular}{|c|c|c|c|c|c|c|}
\hline Exp. & Amine & $\begin{array}{l}\text { Estimated Initial (ppb) } \\
\text { Mixing Ratios }\end{array}$ & Oxidant & Initial $\mathrm{NO}_{x}$ Mixing Ratios (ppb) & $\mathrm{HNO}_{3}$ Injected (ppb) & Atomized Seed Aerosol \\
\hline 1 & Trimethylamine & 100 & $\mathrm{NO}_{\mathrm{x}}$, Propene & $100\left(\mathrm{NO}_{2}\right)$ & - & - \\
\hline 2 & Trimethylamine & 100 & $\mathrm{NO}_{\mathrm{x}}$, Propene & $100\left(\mathrm{NO}_{2}\right)$ & 10 & - \\
\hline 3 & Trimethylamine & 100 & $\mathrm{H}_{2} \mathrm{O}_{2}$ & $100\left(\mathrm{NO}_{2}\right)$ & 10 & - \\
\hline 4 & Trimethylamine & 100 & Ozone & - & 18 & - \\
\hline 5 & Methylamine & 100 & $\mathrm{NO}_{\mathrm{x}}$ & $100\left(\mathrm{NO}_{2}\right)$ & 10 & - \\
\hline 6 & Methylamine & 100 & $\mathrm{H}_{2} \mathrm{O}_{2}$ & $100(\mathrm{NO})$ & 10 & - \\
\hline 7 & Methylamine & 100 & Ozone & - & - & $(\mathrm{NH} 4)_{2} \mathrm{SO}_{4}$ \\
\hline 8 & Triethylamine & 500 & $\mathrm{H}_{2} \mathrm{O}_{2}$ & - & - & - \\
\hline 9 & Triethylamine & 500 & $\mathrm{H}_{2} \mathrm{O}_{2}$ & $400(\mathrm{NO})$ & - & - \\
\hline 10 & Triethylamine & 100 & $\mathrm{NO}_{\mathrm{x}}$ & $100(\mathrm{NO})$ & - & - \\
\hline 11 & Triethylamine & 100 & $\mathrm{NO}_{\mathrm{x}}$ & $100(\mathrm{NO}) 100\left(\mathrm{NO}_{2}\right)$ & - & - \\
\hline 12 & Triethylamine & 100 & $\mathrm{NO}_{\mathrm{x}}$ & $140\left(\mathrm{NO}_{2}\right)$ & - & - \\
\hline 13 & Triethylamine & 100 & $\mathrm{NO}_{\mathrm{x}}$ & $100\left(\mathrm{NO}_{2}\right)$ & - & - \\
\hline 14 & Triethylamine & 100 & $\mathrm{NO}_{\mathrm{x}}$ & $100\left(\mathrm{NO}_{2}\right)$ & 10 & - \\
\hline 15 & Triethylamine & 50 & $\mathrm{NO}_{\mathrm{x}}$, Propene & $100\left(\mathrm{NO}_{2}\right)$ & 100 & - \\
\hline 16 & Triethylamine & 100 & $\mathrm{O}_{3}$ & - & 8 & - \\
\hline 17 & Triethylamine & 100 & $\mathrm{HNO}_{3}$ & - & 100 & - \\
\hline 18 & Triethylamine & 20 ppb TEA aliquots & - & - & - & $\mathrm{NH}_{4} \mathrm{NO}_{3}$ \\
\hline 19 & Triethylamine & $100 \mathrm{ppb} \mathrm{NH}_{3}$ inject TEA in aliquots & - & - & 5 (twice) & - \\
\hline 20 & Triethylamine & $50 \mathrm{ppb}$ TEA $50 \mathrm{ppb} \mathrm{NH}_{3}$ & - & - & 8 & - \\
\hline 21 & Diethylamine & 100 & $\mathrm{H}_{2} \mathrm{O}_{2}$ & - & - & - \\
\hline 22 & Diethylamine & 100 & $\mathrm{H}_{2} \mathrm{O}_{2}$ & $80(\mathrm{NO})$ & - & - \\
\hline 23 & Diethylamine & 100 & $\mathrm{NO}_{\mathrm{x}}$, Propene & $100(\mathrm{NO})$ & - & - \\
\hline 24 & Diethylamine & 100 & $\mathrm{NO}_{\mathrm{x}}$ & $100(\mathrm{NO})$ & - & - \\
\hline 25 & Diethylamine & 100 & $\mathrm{NO}_{\mathrm{x}}$ & $100\left(\mathrm{NO}_{2}\right)$ & - & $(\mathrm{NH} 4)_{2} \mathrm{SO}_{4}$ \\
\hline 26 & Diethylamine & 100 & $\mathrm{NO}_{\mathrm{x}}$ & $100\left(\mathrm{NO}_{2}\right)$ & 10 & - \\
\hline 27 & Ethylamine & 100 & $\mathrm{NO}_{\mathrm{x}}$ & $100\left(\mathrm{NO}_{2}\right)$ & 10 & - \\
\hline 28 & Ethanolamine & 100 & $\mathrm{NO}_{\mathrm{x}}$, Propene & $140 \mathrm{NO} 140 \mathrm{NO}_{2}$ & - & - \\
\hline 29 & Ethanolamine & 100 & $\mathrm{NO}_{\mathrm{x}}$, Propene & $135 \mathrm{NO}_{2}$ & - & - \\
\hline 30 & Ethanolamine & 300 & $\mathrm{NO}_{\mathrm{x}}$, Propene & $100\left(\mathrm{NO}_{2}\right)$ & - & - \\
\hline 31 & Ethanolamine & 100 & - & - & - & $(\mathrm{NH} 4)_{2} \mathrm{SO}_{4}$ mixed with $\mathrm{H}_{2} \mathrm{SO}_{4}(\mathrm{aq})$ \\
\hline 32 & Ethanolamine & 100 & $\mathrm{H}_{2} \mathrm{O}_{2}$ & 100 & 100 & - \\
\hline 33 & Ethanolamine & 100 & $\mathrm{O}_{3}$ & - & - & - \\
\hline 34 & $\mathrm{NH}_{3}$ & 100 & $\mathrm{NO}_{\mathrm{x}}$, Propene & $100\left(\mathrm{NO}_{2}\right)$ & 10 & - \\
\hline
\end{tabular}

Chromatography (PILS-IC), and a differential mobility analyzer (DMA, TSI 3760). During experiment number 20 (Table 2), chamber particles were collected onto a Teflon (PALL Life Sciences, $47-\mathrm{mm}$ diameter, 1.0- $\mu \mathrm{m}$ pore size) filter for analysis by mass spectrometry using both Matrix Assisted Laser Desorption Ionization (MALDI) and electrospray ionization (ESI) to determine how spectra from these ionization techniques compared to the electron impact ionization spectra of the cToF-AMS. Details of the extraction and analysis methodology used for the Teflon filter are given in Surratt et al. (2006).

\section{$2.1 \quad$ PILS-IC}

The particle-into-liquid sampler coupled with ion chromatography is a quantitative technique for measuring watersoluble ions, including inorganic, organic acid, and amine ions in aerosol particles. The PILS-IC used in this study (Sorooshian et al., 2006) is based on the prototype design (Weber et al., 2001) with key modifications, including integration of a liquid sample fraction collector and real-time control of the steam injection tip temperature. Chamber air is sampled through a $1 \mu \mathrm{m}$ cut-size impactor and a set of three denuders (URG and Sunset Laboratories) to remove in- organic (basic and acidic) and organic gases that would otherwise bias aerosol measurements. Sample air mixes with steam in a condensation chamber where rapid adiabatic mixing produces a high water supersaturation. Droplets grow sufficiently large to be collected by inertial impaction before being delivered to vials held on a rotating carousel. The contents of the vials are subsequently analyzed off-line using a dual IC system (ICS-2000 with $25 \mu \mathrm{L}$ sample loop, Dionex Inc.) for simultaneous anion and cation analysis.

Data for the following ions are reported: acetate, formate, nitrate, sulfate ammonium, methylammonium, dimethylammonium, trimethylammonium, ethylammonium, diethylammonium, and triethylammonium. The PILS-IC technique cannot be used to speciate many of the organic compounds that make up the total aerosol mass since these are not sufficiently ionic in water to have affinity for the IC columns used (anion: Dionex AS- 11 column $2 \times 250 \mathrm{~mm}$, ASRS Ultra II 2-mm suppressor, potassium hydroxide eluent; cation: CS12A column $2 \times 250 \mathrm{~mm}$, CSRS Ultra II 2-mm suppressor, methanesulfonic acid eluent); nevertheless, all of the amine salts formed in the experiments reported here were successfully speciated. It should be noted that ammonium, methylammonium, and ethylammonium co-elute; additional co-eluting pairs are diethylammonium:trimethylammonium 
and potassium:dimethylammonium. While potassium was never expected to be present and ammonium formation was not anticipated for many of the experiments, background levels of these species in the IC baseline noise did interfere with quantification of co-eluting species. The limit of detection (LOD) for each ion $\left(\mathrm{NH}_{4}^{+}, \mathrm{NO}_{3}^{-}\right.$, acetate, formate, and the six aforementioned amine species) is defined in this study as the air-equivalent concentration of the lowest concentration standard that is distinct from baseline noise in the IC plus three times the standard deviation $(n=3)$ of this measurement. The LOD's for the ions measured using the PILS-IC technique for this study are all below $0.1 \mu \mathrm{g} \mathrm{m}^{-3}$, with the exceptions of trimethylamine and triethylamine, which have LOD's of 0.60 and $0.89 \mu \mathrm{g} \mathrm{m}^{-3}$, respectively. In all experiments, chamber air containing gas-phase amine and nitric acid (when added) was run through a particle filter and sampled by the PILS-IC; none of the amines was ever detected in these filtered vials, confirming that the carbon denuder was able to completely remove gas-phase species and that the PILS-IC signal is entirely a result of aerosol-phase compounds.

\subsection{Aerodyne cToF-AMS}

The design parameters and capabilities of the cToF-AMS instrument are described in detail elsewhere (Drewnick et al., 2004a, b). Briefly, chamber air enters the instrument through a $100 \mu \mathrm{m}$ critical orifice at a flowrate of $1.4 \mathrm{~cm}^{3} \mathrm{~s}^{-1}$. Particles with a vacuum aerodynamic diameter between roughly 50 and $800 \mathrm{~nm}$ are efficiently focused by an aerodynamic lens, passed through a $1 \%$ chopper, and then impacted onto a tungsten vaporizer. The chopper can be operated in three modes: (1) completely blocking the beam to gather background mass spectra; (2) out of the beam's path to collect ensemble average mass spectra over all particles sizes; (3) chopping the beam to create size-resolved mass spectra. The vaporizer is set at $\sim 550{ }^{\circ} \mathrm{C}$ to ensure complete volatilization of the aerosol. Once vaporized, molecules undergo electron impact ionization at $70 \mathrm{eV}$ and are orthogonally pulsed every $19 \mu$ s into the time of flight mass analyzer. The resolution of the mass analyzer is $\sim 800(\mathrm{M} / \Delta \mathrm{M})$. For all mass spectra shown in this work the ion signal is represented as sticks, the height of which represent the raw ion signal integrated over $1 \mathrm{amu}$ bins. These stick mass spectra are divided into different chemical species based on the methodology of Allan et al. (2003), with exceptions noted in the text. The limits of detection, calculated as three times the standard deviation of the noise for particle filtered air are $<0.05 \mu \mathrm{g} \mathrm{m}^{-3}$ for all species measured.

\subsection{Effective density}

Calculating the density of aerosol particles is important for two reasons. First, multiplying the aerosol volume measured by the DMA by the material density allows one to calculate aerosol mass yields. (The cToF-AMS cannot be used to di- rectly quantify aerosol mass because the fraction of particles that bounce off of the vaporizer is unknown and the PILSIC does not measure the mass of non-ionic species) Second, changes in the density give an indication of alterations in particle morphology during secondary aerosol formation.

The effective density $\left(\rho_{\text {eff }}\right)$ is a function of the vacuum aerodynamic diameter $\left(d_{\mathrm{va}}\right)$ measured by the cToF-AMS and the mobility diameter $\left(d_{\mathrm{m}}\right)$ measured by the DMA (DeCarlo et al., 2004),

$\rho_{\mathrm{eff}}=\frac{d_{\mathrm{va}}}{d_{\mathrm{m}}} \rho_{o}=\rho_{\mathrm{m}} \frac{C_{c}\left(d_{\mathrm{ve}}\right)}{\delta^{3} \chi_{\mathrm{t}} \chi_{\mathrm{v}} C_{\mathrm{c}}\left(d_{\mathrm{m}}\right)}$

where $\rho_{\mathrm{o}}$ is unit density $\left(1 \mathrm{~g} \mathrm{~cm}^{-3}\right), \rho_{\mathrm{m}}$ is the material density, $C_{\mathrm{c}}$ is the slip correction factor, $d_{\mathrm{ve}}$ is the volume equivalent diameter, $\delta$ is a measure of the internal void space defined by $\delta=\left(\rho_{\mathrm{m}} / \rho_{\mathrm{p}}\right)^{1 / 3}$ where $\rho_{\mathrm{p}}$ is the particle density, $\chi_{\mathrm{t}}$ is the dynamic shape factor in the transition regime, and $\chi_{\mathrm{v}}$ is the dynamic shape factor in the free molecular regime.

As described in Bahreini et al. (2005) and Decarlo et al. (2004), the effective density is equivalent to the material density if the shape factor and slip correction factor are unity and the internal void fraction is zero. These assumptions are probably slightly incorrect for amine salts and amine oxidation products, given that ammonium nitrate particles have an effective density 20 percent less than the material density of ammonium nitrate when $\rho_{\text {eff }}$ is calculated using simultaneous cToF-AMS and DMA measurements (Jayne et al., 2000). Indeed the effective densities calculated in this way for the aminium nitrates are less than the literature values. While there is no need to use effective densities to calculate the mass of pure salts (the PILS-IC is able quantitatively measure these), it is necessary to use effective densities (as an approximation of the material density) to calculate the mass of aerosol formed during photooxidation and ozonolysis because non-ionic species are present.

To calculate the effective density, one represents the DMA volume distribution, normally expressed as $\mathrm{d} V / \mathrm{d} \log \left(d_{\mathrm{m}}\right)$, as $\mathrm{d} V / \mathrm{d} \log \left(\rho_{\text {eff }} d_{\mathrm{m}}\right)$ and adjusts $\rho_{\text {eff }}$ until this distribution (with peak height normalized to 1) aligns in diameter space with the mass distribution from the cToF-AMS, $\mathrm{d} M / \mathrm{d} \log \left(d_{\mathrm{va}}\right)$ (peak height also normalized to 1). The two distributions align when the correct effective density is used because $\rho_{\text {eff }} d_{\mathrm{m}}=d_{\mathrm{va}} \rho_{\mathrm{o}}$ (if unity shape and slip correction factors and zero internal void fraction are assumed). Figure 1a shows the calculated effective density of triethylammonium nitrate (TEAN) is $1.0 \pm 0.1 \mathrm{~g} \mathrm{~cm}^{-3}$ while the effective density of the aerosol formed from photolysis of TEA (mixed TEAN and products from TEA oxidation) has a slightly increased effective density of $1.1 \pm 0.1 \mathrm{~g} \mathrm{~cm}^{-3}$.

\subsection{Oxidation experiments}

Three types of amine oxidation experiments were conducted in this study: (1) Photooxidation in the absence of $\mathrm{NO}_{\mathrm{x}}$, (2) 
Photooxidation in the presence of $\mathrm{NO}_{\mathrm{x}}$, and (3) dark ozonolysis. Hydrogen peroxide $\left(\mathrm{H}_{2} \mathrm{O}_{2}\right)$ was used as the $\mathrm{OH}$ radical precursor for all of the $\mathrm{NO}_{\mathrm{x}}$-free photooxidation experiments and many of the high $\mathrm{NO}_{\mathrm{x}}$ experiments (see Table 2 for details). $\mathrm{H}_{2} \mathrm{O}_{2}$ is introduced by bubbling $5 \mathrm{~L} \mathrm{~min}^{-1}$ of humidified room-temperature air for $2.5 \mathrm{~h}$ through a $50 \% \mathrm{H}_{2} \mathrm{O}_{2}$ solution (Aldrich), through a particle filter to avoid the introduction of droplets, and finally into the chamber. The mixing ratio of $\mathrm{H}_{2} \mathrm{O}_{2}$ achieved using this method has been previously estimated to be between 3 and 5 ppm (Kroll et al., 2006). To minimize potential uptake of $\mathrm{H}_{2} \mathrm{O}_{2}$ by the aerosol, all experiments were carried out under dry $(\mathrm{RH}<10 \%)$ conditions. To determine if the presence of hydrogen peroxide significantly affected the particle-phase chemistry, numerous high $\mathrm{NO}_{\mathrm{x}}$ photooxidation experiments were conducted in the absence of $\mathrm{H}_{2} \mathrm{O}_{2}$, some with the gas-phase amine and $\mathrm{NO}_{\mathrm{x}}$ alone, and others where propene was added to generate higher levels of $\mathrm{OH}$ in the chamber and increase the rate of oxidation (see Table 2 for details). For all photooxidation studies, $\mathrm{H}_{2} \mathrm{O}_{2}, \mathrm{NO}_{\mathrm{x}}$, propene, or a combination of these was injected first. For many experiments using $\mathrm{NO}_{\mathrm{x}}$, this step was followed by the injection of nitric acid or, occasionally, ammonium sulfate (see Table 2 for details). After the $\mathrm{HNO}_{3}$ or ammonium sulfate had mixed throughout the chamber, the amine was added. When nitric acid is present, formation of aminium nitrate salt occurs once the amine is injected. By using a similar concentration of $\mathrm{HNO}_{3}$ in all experiments, we were able to roughly control the size distribution of the aerosol. Nucleating the aminium nitrate before the start of oxidation also allowed us to measure the chemistry of pure salt particles in situ with the cToF-AMS and PILS-IC. Photooxidation reactions were initiated by irradiation from the black lights surrounding the chamber. Ozonolysis experiments were conducted in the dark in the absence of an $\mathrm{OH}$ scavenger. The order of reactant introduction for ozonolysis experiments was: nitric acid, amine, and finally ozone. Between experiments, the chamber was continuously flushed with clean air and irradiated with UV light. Contamination from previous experiments was occasionally observed and has been accounted for in the analyses.

\section{Atmospheric reaction pathways of amines}

At the outset, it is useful to frame the results of this study by outlining a hypothesis for the atmospheric reaction pathways of amines. Direct or indirect evidence of most of these pathways has been observed during the chamber experiments in this study.

Because amines are one of relatively few basic atmospheric compounds, they have the potential to undergo rapid acid-base reactions to form salt particles in the presence of nitric or sulfuric acid. Formation of salt particles depends on temperature, the identity of the amine, and the concentrations and identities of acidic species present. Formation

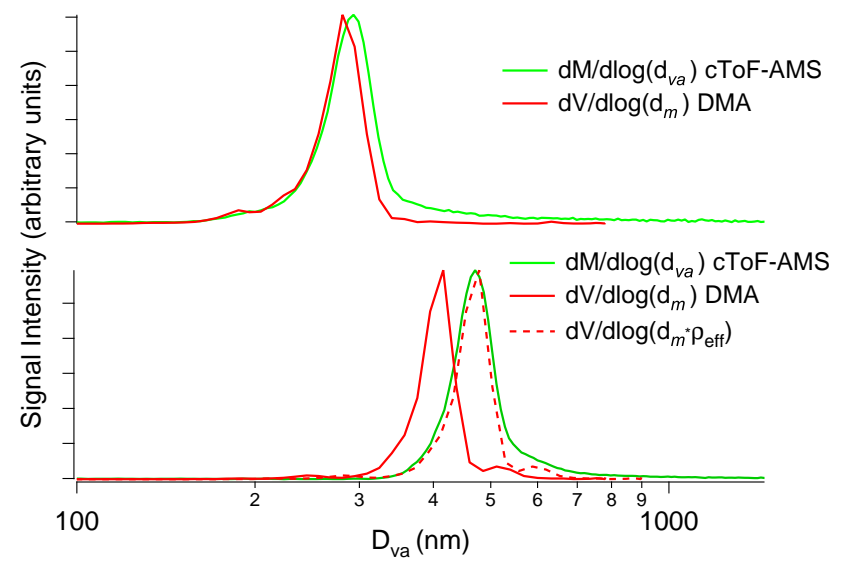

Fig. 1. Calculation of the effective density (data from exp. 14, Table 2). Panel (a) Volume distribution from the DMA $\left(\mathrm{d} V / \mathrm{d} \log \left(\mathrm{d}_{\mathrm{m}}\right)\right.$, solid red line) and mass distribution from the cToFAMS $\left(\mathrm{d} M / \mathrm{d} \log \left(\mathrm{d}_{\mathrm{va}}\right)\right.$, solid green line) of triethylammonium nitrate (TEAN). The fact that the two distributions are aligned indicates the effective density of TEAN is $\sim 1$. The slight tailing of the cToFAMS signal could be caused by slow vaporization or higher uncertainty in the size calibration for larger particles. Panel (b) The same distributions shown in (a) after products from TEA photooxidation have condensed onto the nitrate salt shown in (a) for $7 \mathrm{~h}$. The particles have grown larger from the condensation process. The dashed red line $\left(\mathrm{d} V / \mathrm{d} \log \left(\rho_{\text {eff }} \mathrm{d}_{m}\right)\right)$ is created by adjusting the effective density $\left(\rho_{\text {eff }}\right)$ until the dotted red line aligns with the solid green line $\left(\rho_{\mathrm{eff}}=1.1 \mathrm{~g} \mathrm{~cm}^{-3}\right)$.

of aminium salts also depends indirectly on the concentration of ammonia, which will compete with amines for acidic molecules. Once aminium-salt particles are formed, they can revolatilize, undergo particle-phase reactions (including oxidation), or serve as a site for condensation of other organic species. Condensation of organics onto the salts particles may form a barrier that prevents the salts from remaining at equilibrium with the gas phase.

Gas-phase amines can be oxidized by $\mathrm{OH}, \mathrm{O}_{3}$ and possibly $\mathrm{NO}_{3}\left(\mathrm{OH}\right.$ and $\mathrm{O}_{3}$ are known to be competitive oxidation agents of amines at atmospherically relevant concentrations while the rate of $\mathrm{NO}_{3}$ oxidation remains unexplored). Specifics of the known oxidation pathways will be discussed thoroughly in Sect. 5. Briefly, the products formed depend on the oxidizing species and the $\mathrm{NO}_{\mathrm{x}}$ level. Many of the oxidation products of amines are themselves basic and can undergo reactions with atmospheric acids to form additional salts. Other oxidation products are sufficiently non-volatile to condense directly onto particles without forming salts. Finally, it is possible that certain amines, or their oxidation products, that are too volatile to condense onto dry particles will condense into, and ionize within, aqueous aerosols. Once condensed, amines and their oxidation products may undergo particle-phase reactions to form high molecular weight compounds, or they may be further oxidized into volatile species. 
Table 3. Theoretically calculated dissociation constants for different nitrate systems. $\mathrm{K}_{\mathrm{P}, 298}$ for ammonium nitrate $=7.14 \mathrm{E}-7 \mathrm{~Pa}^{2}$.

\begin{tabular}{lll}
\hline & \multicolumn{2}{c}{$\mathrm{K}_{\mathrm{P}, 298}\left(\mathrm{~Pa}^{2}\right)$} \\
Species & $\Delta \mathrm{H}^{\circ}$ f from Cottrell and Gill (1951) & $\Delta \mathrm{H}^{\circ}$ f from NBS (1982) \\
\hline Methylammonium nitrate & $7.90 \mathrm{E}-06$ & $8.56 \mathrm{E}-09$ \\
Dimethylammonium nitrate & $1.01 \mathrm{E}-05$ & $3.95 \mathrm{E}-09$ \\
Trimethylammonium nitrate & $2.27 \mathrm{E}+00$ & $5.29 \mathrm{E}-07$ \\
Ethylammonium nitrate & $3.29 \mathrm{E}-06$ & $9.56 \mathrm{E}-07$ \\
Diethylammonium nitrate & $3.11 \mathrm{E}-10$ & $3.30 \mathrm{E}-11$ \\
Triethylammonium nitrate & $1.37 \mathrm{E}-05$ & $1.18 \mathrm{E}-12$ \\
\hline
\end{tabular}

The remainder of the paper is divided into two main sections. In the first section, we investigate salt aerosol formation from acid-base reactions of amines through both laboratory chamber experiments and theoretical estimates. In the second section, aerosol formation resulting from photooxidation and ozonolysis of amines under varying $\mathrm{NO}_{\mathrm{x}}$ conditions is addressed.

\section{Salt aerosol formation from acid-base reactions of amines}

\subsection{Detection of aminium nitrate salts}

As described in the Experimental section, nitrate salts were formed by adding the amine of interest to a chamber containing gaseous nitric acid $\left(\mathrm{HNO}_{3}\right)$. In all cases, particle nucleation occurred within a few minutes of amine injection. All of the aminium nitrate salts investigated were detected by the cToF-AMS, PILS-IC, and DMA instruments. The mass spectra for the nitrate salts of the amines studied are shown in Fig. 2. The spectra are similar to reference electron impact spectra in the NIST database for the gas-phase amines except for additional intensity at $\mathrm{m} / \mathrm{z} 30$ and $\mathrm{m} / \mathrm{z} 46$ caused by $\mathrm{NO}^{+}$ and $\mathrm{NO}_{2}^{+}$ion fragments from nitrate (Stein, 2005). The only previous chamber study to focus on aerosol-phase amines was conducted by Angelino et al. (2001) using a laser desorption aerosol time of flight mass spectrometer (ATOFMS). In their study, the spectra of dialkyl ammonium salts exhibited prominent peaks $(\mathrm{M}+13)^{+}$, attributed to ion-molecule reactions within the ionization region of the instrument. We do not observe peaks larger than the molecular ion for any of the salts, indicating that ion-molecule reactions do not occur in the ionization region of the Aerodyne cToF-AMS; this absence of ion-molecule reactions dramatically simplifies mass spectral interpretation.

Though we did not observe ion-molecule reactions, it is important to note that we did observe a dramatic increase in the number of ions detected by the cToF-AMS when the voltages that extract ions from the electron impact region into the flight chamber of the mass spectrometer were al- tered by a few percent. When the voltages were in this altered state, we observed a further increase in both molecular and fragment amine ions with increasing vaporizer temperature above $550^{\circ} \mathrm{C}$. No such correlation between increased vaporizer temperature and ion signal is observed when the extraction voltages are not in the altered state. Because altering the extraction voltages allows ions formed on the vaporizer surface to enter the mass spectrometer and because amines have low ionization potentials, we believe that the additional ions are formed on the high temperature tungsten surface of the vaporizer. The artificial signal enhancement (increased ion rate) caused by this proposed surface ionization indicates that there is a potential for overestimates of amine concentrations measured by the Aerodyne cToF-AMS if the instrument is not carefully callibrated and tuned. Similar effects caused by the unusually low ionization energy of amines may also occur in other aerosol mass spectrometry instruments. We observed enhancement of up to an order of magnitude by changing the voltages in the instrument a few percent. The $m / z$ with the most prominent increase in ion rate was that corresponding to the molecular ion of the amine being studied. The fact that the molecular ion showed the most dramatic increase further supports the hypothesis that a non-electron impact surface ionization is occurring; $70 \mathrm{eV}$ electron impact ionization typically induces alpha cleavage of amines and little, non-fragmented, molecular ion signal is observed. It should be noted that we have not observed an increase in detected ions when the extraction voltages are shifted when studying aerosol that does not contain amines. Though not investigated further, these observations raise the possibility that this type of tuning might be intentionally used to detect the presence of molecular amine ions.

\subsection{Atmospheric formation of aminium nitrate salts: theory}

Having confirmed that aminium nitrate salts can be generated and detected, we wish to estimate the potential atmospheric importance of aminium nitrate salts relative to ammonium nitrate (typically assumed to be the dominant atmospheric nitrate salt in the fine mode). Based on theory, we estimate the dissociation constants $\left(K_{\mathrm{p}}=p_{\mathrm{HNO}_{3}} p_{\text {amine }}\right)$ 


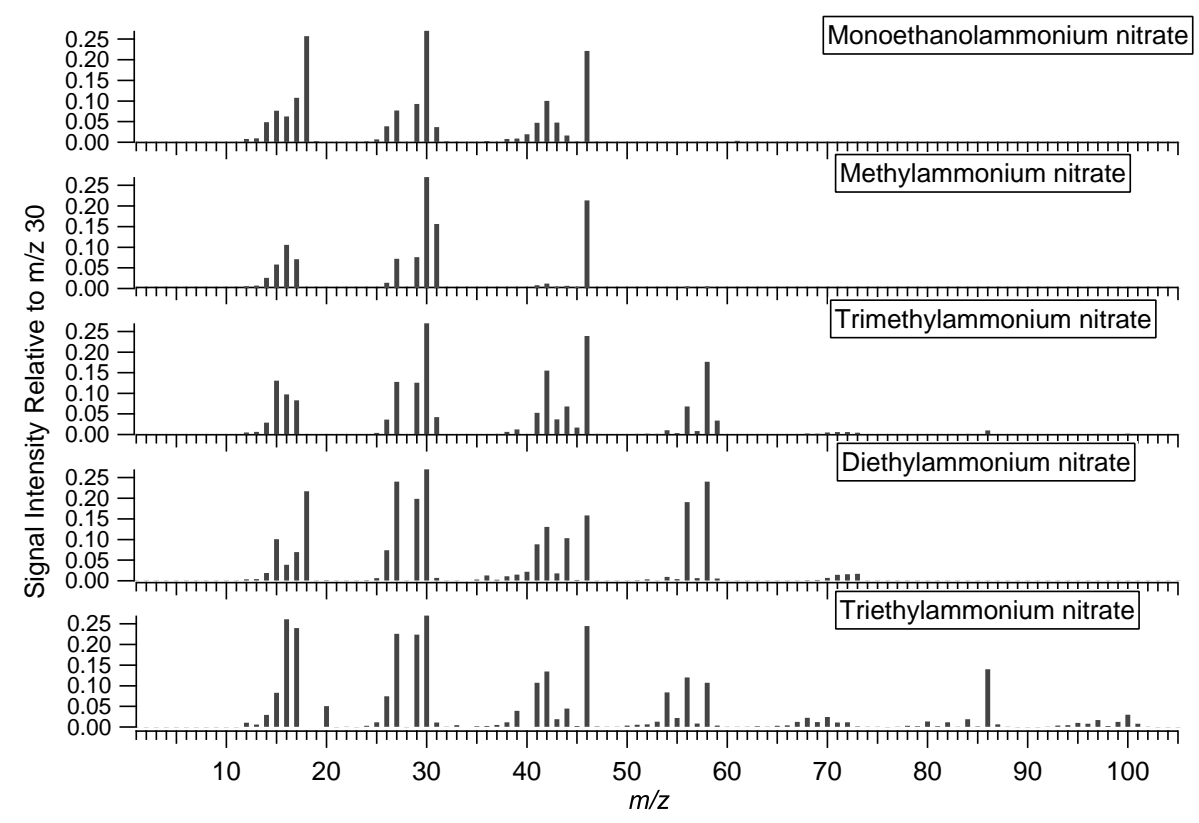

Fig. 2. Mass spectra for the nitrate salts of the amines studied. On the $\sim 550^{\circ} \mathrm{C}$ surface of the vaporizer, all nitrate salts decompose into nitric acid and the parent amine. Signals at $m / z \quad 30$ and 46 are generated from the nitrate fragments $\mathrm{NO}^{+}$and $\mathrm{NO}_{2}^{+}$and are common to all spectra. Signal at $\mathrm{m} / \mathrm{z} 30$ is a combination of signal from $\mathrm{NO}^{+}$and from amine fragments resulting from rearrangements after electron impact ionization. For all spectra, molecular ions have significantly less signal intensity than the fragments resulting from the cleavage of the chemical group alpha to the nitrogen (alpha cleavage). For the ethyl amines, loss of methyl groups alpha to the nitrogen give fragments at $[\mathrm{M}-15]^{+}$while for the methyl amines, loss of hydrogen atoms alpha to the nitrogen give fragments at $[\mathrm{M}-1]^{+}$.

for the gas-particle equilibrium of all amines studied except for ethanolamine, while noting that the estimates have large uncertainties resulting from discrepancies in the literature values for the heats of formation of the aminium nitrate salts. If the required thermodynamic parameters are known, the dissociation constant for a given amine-nitric acid system can be obtained using the integrated form of the Van't Hoff equation,

$$
\begin{aligned}
\ln K_{\mathrm{P}} & =\frac{\Delta S_{\mathrm{diss}}^{\circ}-\Delta C_{\mathrm{P}, \mathrm{diss}}}{R}-\frac{\Delta H_{\mathrm{diss}}^{\circ}-T_{0} \Delta C_{\mathrm{P}, \mathrm{diss}}}{R T} \\
& +\frac{\Delta C_{\mathrm{P}, \mathrm{diss}}}{R} \ln \left(\frac{T}{T_{0}}\right)
\end{aligned}
$$

Entropies of formation for aminium nitrate salts have apparently not been reported in the literature; we estimate them using a molecular dynamics approach described in the Appendix. Also given in the Appendix are literature sources and values for the other thermodynamic parameters in Eq. (2). The calculated dissociation constants for all of the amines studied (except ethanolamine, for which the entropy was not estimated) are given in Table 3. Even if we assume that the estimated entropies are accurate, the results in Table 3 show that discrepancies in the literature values for the heats of formation lead to significant uncertainty in the calculated dissociation constants. While this uncertainty precludes us from gaining meaningful insight into how MA, DMA, or TEA might compete with ammonia for $\mathrm{HNO}_{3}$ in the atmosphere, we are able to draw conclusions about the other salts. As mentioned earlier, most studies show that ambient ammonia concentrations tend to be an order of magnitude greater than amine concentrations, except perhaps in the immediate vicinity of an amine emissions source. Given this, and assuming that the calculated entropies are reasonable, it is improbable that nitrate salts of TMA or EA would form in the presence of typical ambient ammonia levels, because the $K_{\mathrm{p}}$ values for these two systems are greater than or equal to that of ammonium nitrate, independent of the precise value of the heat of formation. By contrast, the value of the dissociation constant for DEA is 2 to 3 orders of magnitude smaller than that of ammonium nitrate (independent of the uncertainty in the heat of formation), indicating that formation of DEAN particles under typical atmospheric mixing ratios is possible.

\subsection{Atmospheric formation of aminium nitrate salts; exper- imental}

We conducted chamber experiments to evaluate and constrain the theoretical estimate for the dissociation constant of triethylammonium nitrate (TEAN), the highest molecular weight aminium nitrate studied.

The first experiment was carried out to study TEAN formation at atmospherically relevant ratios of ammonia:TEA (Fig. 3). Initially, $100 \mathrm{ppb}$ of gas-phase ammonia was mixed in a chamber containing $\sim 5 \mathrm{ppb}$ of nitric acid, leading to 

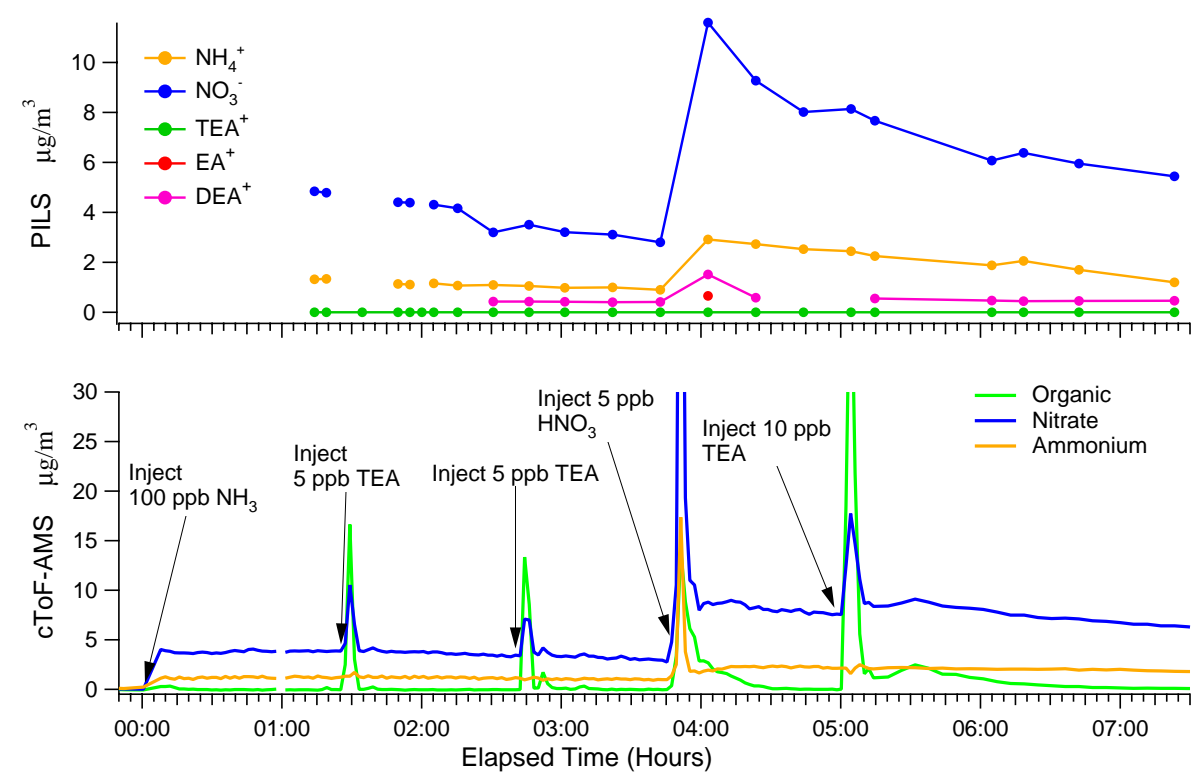

Fig. 3. Time series from exp. 19 in Table 2 of the cToF-AMS (bottom) and the PILS-IC (top) showing rapid particle growth and evaporation after TEA and nitric acid were added in small aliquots to a chamber containing equilibrated ammonium nitrate particles. The transient spikes in particle loading do not appear in the PILS-IC data because of the relatively long averaging time ( 5 min) of measurements and because the PILS-IC inlet is not in the path of the highly concentrated injection plume.

nucleation of ammonium nitrate particles. Once the ammonium nitrate particle concentration and mass had stabilized, aliquots of TEA were injected into the chamber. As can be seen in Fig. 3, the concentration of TEAN salt, indicated by simultaneous shifts in the nitrate and organic signals, increased dramatically when TEA was added because the injection plume provided a high concentration region for particle formation. As the amine mixed throughout the chamber and became more dilute, the equilibrium shifted back to the gas phase, the salt returned to pure ammonium nitrate, and the organic signal $=0$. This sequence of events occurred after each injection, including a second addition of $5 \mathrm{ppb}$ of nitric acid to the chamber.

After concluding that TEA would be unable to form nitrate salts at ratios of TEA: $\mathrm{NH}_{3}$ typically found in the atmosphere (except possibly near emissions sources), we developed an experimental technique to estimate the gas-particle equilibrium constant for TEAN. The procedure consists of adding an equimolar mixture of amine and ammonia to a chamber containing nitric acid (it is necessary to inject both ammonia and amine because we are unable to accurately measure gasphase amine or nitric acid concentrations). Once ammonia, TEA, and nitric acid are injected, the following equilibria are established:

$K_{\mathrm{P} 1}=p_{\mathrm{HNO}_{3}} p_{\mathrm{NH}_{3}}$

$K_{\mathrm{P} 2}=p_{\mathrm{HNO}_{3}} p_{\mathrm{TEA}}$

where $p_{\mathrm{HNO}_{3}}, p_{\mathrm{NH}_{3}}$, and $p_{\mathrm{TEA}}$ are the partial pressures of nitric acid, ammonia, and triethylamine, and $K_{\mathrm{P} 1}$ and $K_{\mathrm{P} 2}$ are the dissociation constants for ammonium nitrate and triethylammonium nitrate, respectively. Using the values in Table A1 in Eq. (2), $K_{\mathrm{P} 1}$ for the ammonium nitrate system is calculated to be $1.916 \mathrm{E}-7 \mathrm{~Pa}^{2}$ at $293 \mathrm{~K}$. The partial pressures of $\mathrm{NH}_{3}$ and TEA can be determined by subtracting the measured mass of each species in the aerosol phase from that which was injected, assuming negligible wall loss. Thus $K_{\mathrm{P} 2}$ and $p_{\mathrm{HNO}_{3}}$ are the two unknown quantities to be determined. Although the PILS-IC can measure the amount of nitrate in the aerosol phase, this measurement was not used to calculate $p_{\mathrm{HNO}_{3}}$, as nitric acid is subject to significant wall losses.

We report here an experiment in which $50 \mathrm{ppb}$ of TEA and $50 \mathrm{ppb}$ of ammonia were added simultaneously to a chamber containing $8 \mathrm{ppb}$ of nitric acid. Upon injection of the amine/ammonia mixture, a rapid particle nucleation event was detected by the cToF-AMS (similar to those shown in Fig. 3). As the plume of ammonia and TEA mixed through the chamber, the mass loading of particles detected by the cToF-AMS decreased, and the other particle instruments (PILS-IC and DMA, which are not aligned with the injection port) began to detect particle loadings consistent with those of the cToF-AMS. After all of the instruments gave consistent readings and the particle concentration was stable (other than a slow decrease from wall loss), the triethylammonium and ammonium contents of the aerosol-phase were measured by the PILS-IC, which unambiguously and quantitatively detects these two species. The dissociation constant of triethylammonium nitrate determined from this experiment, using Eq. (4), is $1.85 \mathrm{E}-7 \mathrm{~Pa}^{2}$. Although wall losses and slight 


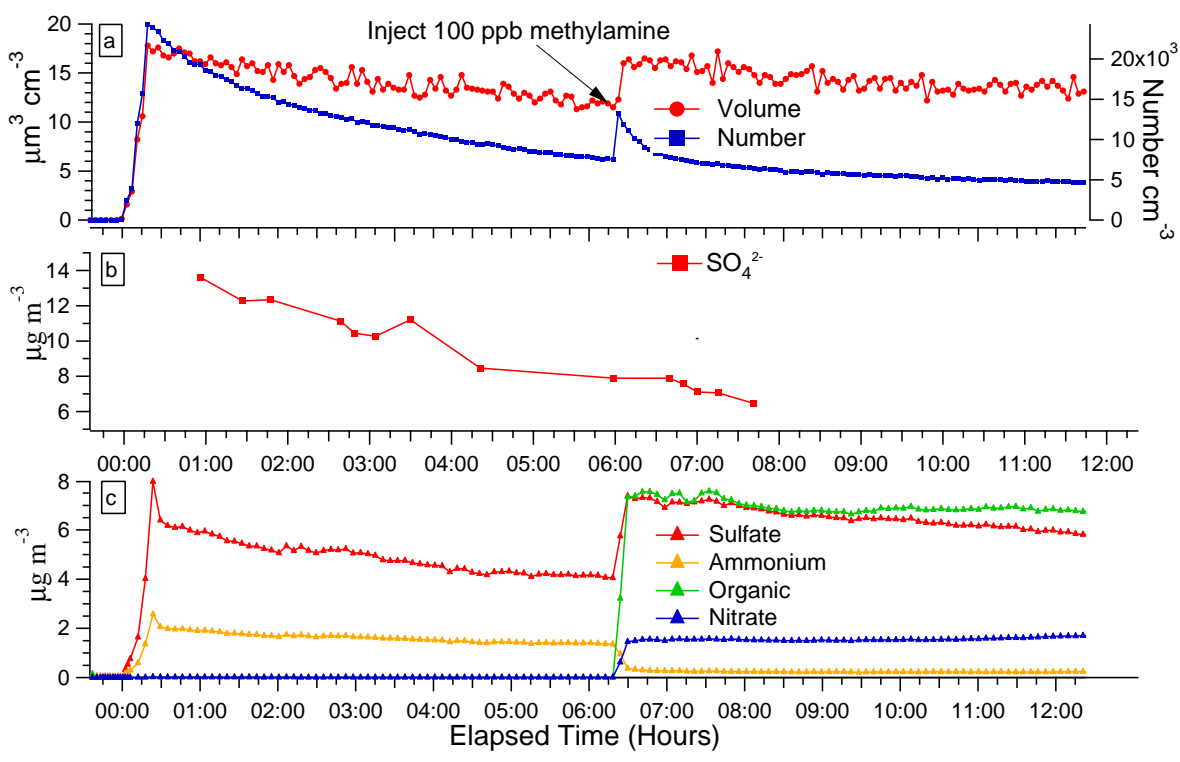

Fig. 4. Time Series of data from the DMA Panel (a), PILS-IC Panel (b), and cToF-AMS Panel (c) showing rapid replacement of ammonium sulfate by methylammonium sulfate during the injection of $100 \mathrm{ppb}$ of methylamine into a chamber containing ammonium sulfate seed and ozone. The increase in the ratio of organic signal to sulfate signal near the end of the experiment results from the slow reaction of methylamine with ozone forming a small mass of organic aerosol.

contamination from other amine compounds from previous experiments influenced this result, the likely effect of these influences is judged to be too small to affect the conclusion that the dissociation constant for TEAN is close to that of ammonium nitrate. This conclusion is consistent with the previous experiment and the estimated dissociation constant falls within the large range of values predicted theoretically.

The two chamber experiments described above confirm that TEA does not form nitrate salts unless the ammonia concentration is roughly equivalent to that of TEA or there is a large excess of nitric acid. Experimental testing of all of the amines was beyond the scope of this study and further studies of this type are warranted, but these initial results indicate that the calculated dissociation constants, although subject to considerable uncertainty, are reasonable.

\subsection{Aminium sulfate salts}

Amines have the potential to form sulfate salts analogous to ammonium sulfate. Although nitrate salts are probably more relevant in agricultural settings, aminium sulfate salts may form in the presence of high sulfate concentrations. Figure 4 shows results from the addition of $100 \mathrm{ppb}$ methylamine (MA) to pure ammonium sulfate seed in a dry (less than $10 \% \mathrm{RH}$ ) chamber (the chamber also contained ozone because the experiment was designed for MA ozonolysis). The DMA data show a $3 \mu \mathrm{m}^{3} \mathrm{~cm}^{-3}$ increase in particle volume and new particle formation when methylamine is injected. The new particles are formed from the reaction of methylamine with residual nitric acid in the chamber.
Intriguingly, the mass of methylammonium (labeled "organic" in Fig. 4) detected by the cToF-AMS is roughly 8 times the mass needed to neutralize the nitrate. Additionally, the time series from the cToF-AMS also shows a sharp decrease in the ammonium signal as the methylamine signal increases. The effective density of the particles decreases slightly $\left(\sim 0.1 \pm 0.1 \mathrm{~g} \mathrm{~cm}^{-3}\right)$ as the organic signal increases. All of these trends indicate that the methylamine is displacing ammonia and forming methylammonium sulfate. One oddity is the apparent increase in sulfate observed by the cToF-AMS. The sulfate time series from the PILS-IC shows that there is no increase in sulfate loading after methylamine is injected (the growth of methylammonium cannot be followed by the PILS-IC because the IC column used is unable to distinguish between ammonium and methylammonium cations). The increase in sulfate signal from the cToFAMS can most easily be explained as an artifact, often seen in chamber studies, resulting from an increase in collection efficiency as the physical properties of the aerosol change (Bahreini et al., 2005; Huffman et al., 2005). We hypothesize that replacement of the ammonium cation by methylammonium alters the physical characteristics of the particle which, in turn, causes fewer particles to bounce from the vaporizer surface, increasing collection efficiency. All of the signals from the cToF-AMS (sulfate, organic, nitrate and ammonium) have been scaled by a factor that causes the cToFAMS sulfate mass to match the PILS-IC sulfate mass after the increase in collection efficiency. Accordingly, the masses shown for the cToF-AMS before the collection efficiency increase are low. 
Though the gas-phase concentration of methylamine in this experiment is relatively large, a nearly complete conversion from ammonium sulfate to methylammonium sulfate was observed. The extent of this type of displacement at lower gas-phase amine concentrations, for other amines, and as a function of RH all warrant further study.

\section{Aerosol formation from photooxidation and ozonoly- sis of amines}

We begin this section by describing common trends observed during the oxidation experiments of all amines. The following subsections give the data and details for the oxidation of individual amines.

During all of the photooxidation experiments with $\mathrm{NO}_{\mathrm{x}}$, we observed aerosol growth resulting from a combination of aminium nitrate salt formation and condensation of nonvolatile oxidized compounds (growth from the dissolution of water soluble amines was limited by the low, $<10 \%$, $\mathrm{RH}$ of the chamber). For all of the amines studied, some of the aminium nitrate salt that was initially formed during photooxidation partitioned back into the gas-phase as more of the parent amine was reacted away. The particle-phase salt repartitions back to the gas phase because the continued oxidation of the parent amine depletes its concentration in the gas phase and drives the equilibrium back towards gasphase amine and nitric acid. For methylamine, ethylamine, ethanolamine, and diethylamine nearly 100 percent of the nitrate salt revolatilized while for trimethylamine and triethlyamine the nitrate salts appeared to be more stable and did not return completely to the gas phase. All experiments were carried out until the mass of aerosol was stable, no further growth or decay other than a slow decay caused by particle loss to the walls. Based on estimates of the $\mathrm{OH}$ concentration in our chamber (Kroll et al., 2006) and measured ozone concentrations, the cessation of aerosol growth is not caused by a depletion of oxidant. Typically, one defines a mass yield of secondary organic aerosol (ratio of organic aerosol mass to the mass of hydrocarbon reacted), but for the amines the mass yield of aerosol depends on the concentration of nitric acid in the system. If ample nitric acid is formed during photooxidation, nearly all of the amine will form aminium nitrate salts, while in the absence of nitric acid, nitrate salts are not formed and the yield reflects the formation of nonvolatile compounds from reaction of $\mathrm{OH}$ and $\mathrm{O}_{3}$ with the amine. Additional complexity arises because many of the oxidation products of amines are themselves basic and can form salts with nitric acid (e.g. amides and imines can all form salts with $\mathrm{HNO}_{3}$ ). These factors create a situation in which the yield of aerosol is related in a complex manner to the rate of formation of nitric acid in the system.

If all of the nitrate salts return to the gas phase as the parent amine is reacted away, the final aerosol mass yield would be relatively independent of the nitric acid concentra- tion. Intriguingly, this is not the case for experiments involving TMA or TEA, as the PILS-IC detects significant loadings of salt at the end of these experiments. As described in detail later in this section, TMA and TEA are the only two amines that formed significant non-salt organic aerosol during oxidation. One explanation for the persistence of the aminium nitrate salts in these two systems is that the salt has been "trapped" inside an external layer of oxidized aerosol and is no longer in equilibrium with the gas phase. However, the timescale for diffusion through the organic layers formed in these experiments, which are less than $200 \mathrm{~nm}$ thick, is small and, unless the gas phase amine was completely insoluble in the organic layer, it is improbable that this layer could "trap" the salt for any significant amount of time. It is possible that mixing of organic material with the salt in the particle phase somehow lowers the volatility of the salt. Another possibility is that gas-phase concentrations of nitric acid are sufficiently high to force the equilibrium towards the particle phase even when the concentration of the parent amine is very low. Finally, given the large uncertainties in the calculated gas-particle equilibrium constants for the amines, it is possible that certain amines favor the particle phase even at very low gas-phase concentrations.

Regardless of the mechanism by which the salts persist, the formation of nitrate salts biases the calculated mass yields of the photooxidation experiments to be higher than they would be as a result of oxidation alone. In an attempt to estimate the purely oxidative yield in the absence of salt formation we conducted ozonolysis experiments and photooxidation experiments in the absence of $\mathrm{NO}_{\mathrm{x}}$. The aerosol mass yields for the different amines during photooxidation (with and without $\mathrm{NO}_{x}$ ) and ozonolysis are given in Table 4. It is important to note that these yields are derived from experiments run under a single set of conditions and are given to show relative differences in the behavior of the different amines; they are not quantitative yield estimates for the individual amines. Indeed, runs conducted with higher initial concentrations of amine give higher yields because of the increased particle-phase organic mass into which organics can condense (Seinfeld and Pankow, 2003). It is even possible that the mass of salt formed can affect the yield if the condensable organics formed are soluble in the nitrate salts. Because of the exploratory nature of this study and because of the complex behavior of amines forming aerosol both through salt formation and oxidation, we do not attempt to derive yield curves from these data.

The non-salt photooxidation yields given in Table 4 were obtained using the following method: first, the aerosol volume measured by the DMA was multiplied by the effective density; second, the salt fraction of the aerosol mass was determined as (PILS-IC mass)/(DMA volume $\times$ effective density). Finally, the wall-loss corrected DMA volume was multiplied by the effective density and then by the fraction of non-salt aerosol mass to give the mass of non-salt secondary organic aerosol (SOA). The yields were calculated using data 
Table 4. Estimated percent mass yields ${ }^{\mathrm{a}}$ of non-salt aerosol during ozonolysis and photooxidation. All yields have an uncertainty of $\sim 25 \%$ of their magnitude.

\begin{tabular}{cccc}
\hline Amine & Ozonolysis Yield & High $\mathrm{NO}_{x}$ Photooxidation Yield & Zero $\mathrm{NO}_{x}$ Photooxidation Yield \\
\hline Trimethylamine & 15 & $23^{\mathrm{b}}$ & - \\
Methylamine & $<1$ & $<1^{\mathrm{b}}$ & - \\
Triethylamine & 5 & $8^{\mathrm{c}}$ & $12^{\mathrm{b}}$ \\
Diethylamine & $<1$ & $<1^{\mathrm{b}}$ & $<1^{\mathrm{b}}$ \\
Ethylamine & - & $<1^{\mathrm{c}}$ & - \\
Ethanolamine & 3 & $2^{\mathrm{c}}$ & - \\
\hline
\end{tabular}

${ }^{\mathrm{a}}$ All yields for high $\mathrm{NO}_{\mathrm{x}}$ and ozonolysis are derived from experiments using $100 \mathrm{ppb}$ initial concentrations of amine (high $\mathrm{NO}_{\mathrm{x}}$ photooxidations were run with $100 \mathrm{ppb}$ of $\mathrm{NO}_{\mathrm{x}}$ ). The zero $\mathrm{NO}_{\mathrm{x}}$ yields are from experiments using $500 \mathrm{ppb}$ initial amine concentrations. These yields are given to demonstrate trends in the aerosol forming potential of the different amines and are not meant to represent definitive yields for the systems shown.

${ }^{\mathrm{b}} \mathrm{H}_{2} \mathrm{O}_{2}$ as $\mathrm{OH}$ precursor.

${ }^{c}$ Photooxidation without $\mathrm{H}_{2} \mathrm{O}_{2}$. Photooxidation of $500 \mathrm{ppb}$ TEA using $\mathrm{H}_{2} \mathrm{O}_{2}$ gave a mass yield of non-salt organic aerosol of $>20 \%$.

${ }^{\mathrm{d}}$ The effective densities used for the yield calculations are: TMA Ozonolysis: 1.4; TMA High NO $\mathrm{x}_{\mathrm{x}}$ photox: 1.3; TEA Ozonolysis: 1.2; TEA High $\mathrm{NO}_{\mathrm{x}}$ photox: 1.1; TEA Low $\mathrm{NO}_{\mathrm{x}}$ photox: 1.1. All effective densities are given in $\mathrm{g} \mathrm{cm}^{-3}$ with uncertainties of $\pm 0.1 \mathrm{~g} \mathrm{~cm}^{-3}$.

from the period after aerosol growth and decay appeared to have ceased other than from loss to the chamber walls. These yield results will be discussed in detail later, although it is immediately evident that while all of the amines can generate aerosol mass by forming nitrate salts, several do not form aerosol mass through oxidation.

Before discussing results from individual photooxidation and ozonolysis experiments, it is useful to consider the general mechanisms by which $\mathrm{OH}$ and ozone oxidize aliphatic amines. The gas-phase chemistry of amine oxidation by $\mathrm{OH}$ (in the presence of $\mathrm{NO}_{\mathrm{x}}$ ) and by ozone (without $\mathrm{NO}_{\mathrm{x}}$ ) have been studied (Schade and Crutzen, 1995; Tuazon et al., 1994), and the major products formed by these reactions have been identified. For many of the oxidation pathways, the products of $\mathrm{OH}$ and ozone oxidation are similar, if not identical. The gas-phase products formed from oxidation of aliphatic amines by $\mathrm{OH}$ in low $\mathrm{NO}_{\mathrm{x}}$ environments are unknown.

Figure 5a shows the most common oxidation pathways for $\mathrm{OH}$ attack of an aliphatic amine in the presence of $\mathrm{NO}_{\mathrm{x}}(\mathrm{An}-$ gelino et al., 2001; Schade and Crutzen, 1995). Abstraction of hydrogen from the secondary carbon is believed to be the dominant pathway (Finlayson-Pitts and Pitts, 1986). Abstraction of a hydrogen atom bound directly to the nitrogen in a primary or secondary amine is also possible but is believed to play a less significant role (Schade and Crutzen, 1995). The gas-phase oxidation products formed are amides, nitramines, and imines. All of the products shown have the potential to partition to the aerosol phase, although amides are particularly water soluble and have the lowest vapor pressures. An unexpected product, alkylamine-N-oxide, was first detected by Angelino et al. (2001) in the aerosol phase and was again detected in the particle phase during the current study.
Figure $5 \mathrm{~b}$ shows the pathways for ozone reaction with an aliphatic amine. While the loss of an alkyl group from the high energy amine oxide generates products distinct from those generated by reaction with $\mathrm{OH}$, rearrangement of the amine oxide and subsequent loss of $\mathrm{OH}$ leads to alkoxy radicals similar to those generated from hydrogen abstraction by $\mathrm{OH}$ followed by loss of an oxygen atom to NO. Following this branch of the reaction diagram leads to similar, and in many cases identical, products as those formed by reaction with $\mathrm{OH}$.

Figure $5 \mathrm{c}$ shows the beginning of the reaction pathways for amine oxidation by $\mathrm{OH}$ in the absence of $\mathrm{NO}_{\mathrm{x}}$. Presumably, a number of the condensable species in this system consist of hydroperoxides and alkyl peroxides. Many of the same products formed in the high $\mathrm{NO}_{\mathrm{x}}$ and ozone systems are formed if, rather than forming peroxides, $\mathrm{RO}_{2}+\mathrm{RO}_{2}$ and $\mathrm{RO}_{2}+\mathrm{HO}_{2}$ reactions form alkoxy radicals.

Many of the photooxidation experiments reported here employed hydrogen peroxide $\left(\mathrm{H}_{2} \mathrm{O}_{2}\right)$ as an $\mathrm{OH}$ source. As detailed in the Experimental section, a relatively large amount (3-5 ppm) of hydrogen peroxide must be introduced into the chamber to achieve sufficient levels of $\mathrm{OH}$ for rapid reaction. Because the reaction between $\mathrm{OH}$ and $\mathrm{H}_{2} \mathrm{O}_{2}$ forms $\mathrm{HO}_{2}$ and because hydrogen peroxide itself may affect the chemistry of the aerosol formed, we conducted additional photooxidation experiments using mixtures of propene and $\mathrm{NO}_{\mathrm{x}}$ as well as $\mathrm{NO}_{\mathrm{x}}$ alone. We found no major differences in chemistry between the systems with and without $\mathrm{H}_{2} \mathrm{O}_{2}$, although the reactions occurred much faster in the presence of hydrogen peroxide, as expected. All of the ozonolysis reactions were carried out in the absence of $\mathrm{NO}_{\mathrm{x}}$. 


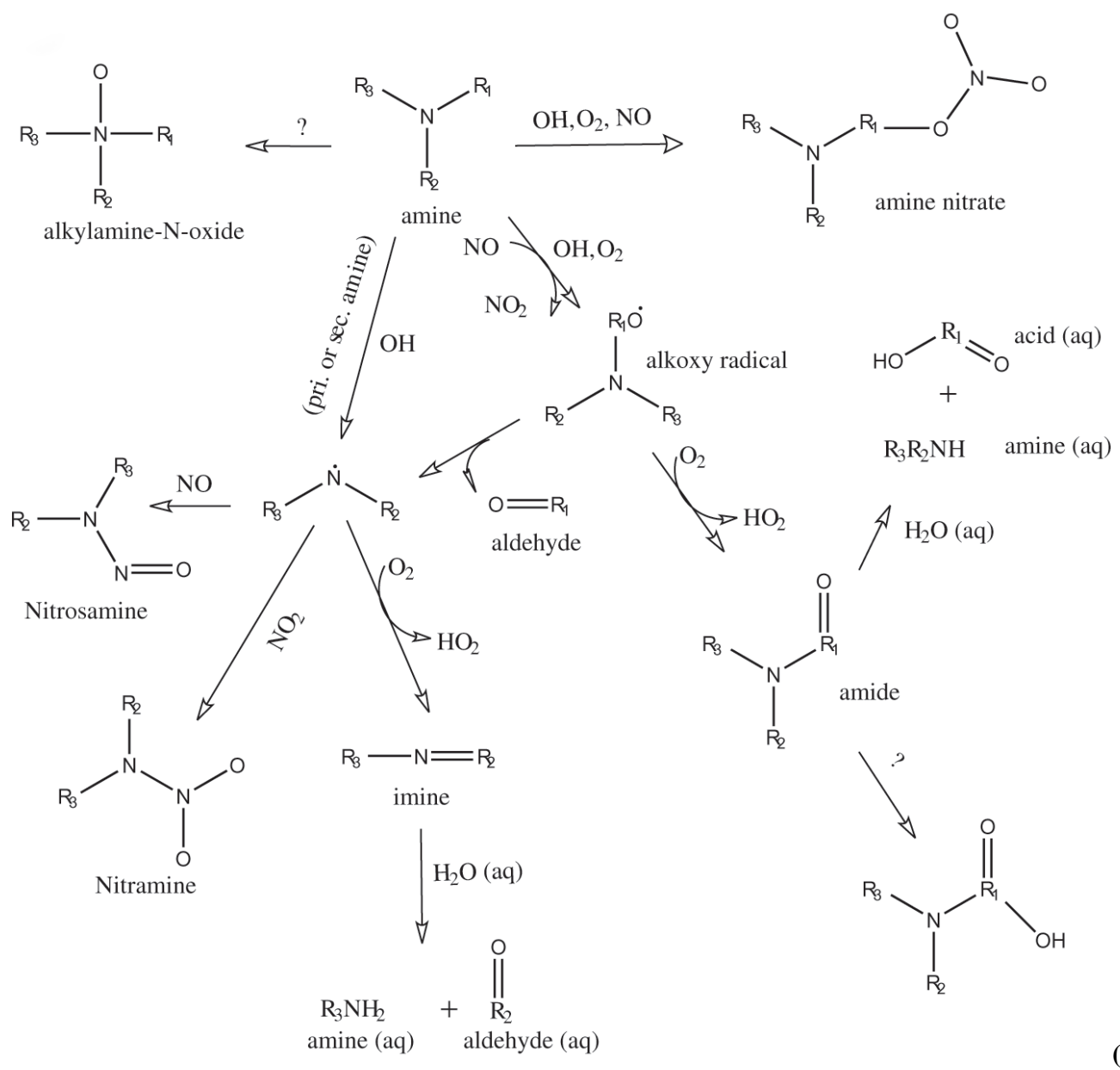

Fig. 5a. Mechanism of amine oxidation by $\mathrm{OH}$ in the presence of $\mathrm{NO}_{\mathrm{x}}$ (Schade and Crutzen, 1995).

\subsection{Experimental protocol}

The same procedure was used for all photooxidation and ozonolysis experiments. For photooxidation experiments, the first step is the injection of either: $\mathrm{H}_{2} \mathrm{O}_{2}, \mathrm{a}_{2} \mathrm{O}_{2}$ and $\mathrm{NO}_{\mathrm{x}}$ mixture, a $\mathrm{NO}_{\mathrm{x}}$ and propene mixture, or $\mathrm{NO}_{\mathrm{x}}$ alone. Table 2 gives the oxidant used and $\mathrm{NO}_{\mathrm{x}}$ mixing ratio for each photooxidation experiment. For all types of experiments, except $\mathrm{NO}_{\mathrm{x}}$-free photooxidations, the next step was to add a small amount ( $\sim 10 \mathrm{ppb})$ of $\mathrm{HNO}_{3}$. Once the $\mathrm{HNO}_{3}$ had mixed, the amine was injected at a much higher concentration than the nitric acid (typically $\sim 100 \mathrm{ppb}$ ) causing nucleation of aminium nitrate salt while the vast majority of the amine remained in the gas phase. The concentration of nucleated salt particles was always observed to peak soon after the injection of the amine, followed by a sharp decrease in mass as mixing occurred and gas-particle equilibrium was established.

After the concentration of the nucleated particles became steady and sufficient time had elapsed to collect composition data with the cToF-AMS and the PILS-IC, oxidation was ini- tiated. For photooxidation experiments, oxidation was initiated by turning on the black lights surrounding the chamber, while for ozonolysis ozone was injected into the chamber. All experiments were continued until there were no further changes in particle mass or volume, except for slow decay in mass and volume caused by particle loss to the chamber walls.

\subsection{Trimethylamine (TMA) photooxidation}

Trimethylamine (TMA) is one of the more abundant ambient alkyl amines near animal husbandry operations (Rabaud et al., 2003; Schade and Crutzen, 1995). Figure 6 shows the time profiles for $\mathrm{NO}_{\mathrm{x}}, \mathrm{O}_{3}$, particle volume (DMA), ionic particle mass (PILS-IC), and particle mass (cToF-AMS) during the photooxidation of TMA. For this experiment (number 3, Table 2), $300 \mathrm{ppb}$ of $\mathrm{NO}_{2}, 10 \mathrm{ppb}$ of $\mathrm{HNO}_{3}$ and $100 \mathrm{ppb}$ of TMA were used. As expected, trimethylammonium nitrate (TMAN) salt began to nucleate soon after the injection of TMA. Approximately $30 \mathrm{~min}$ after the TMA injection the aerosol mass stabilized as the system reached gas-particle 

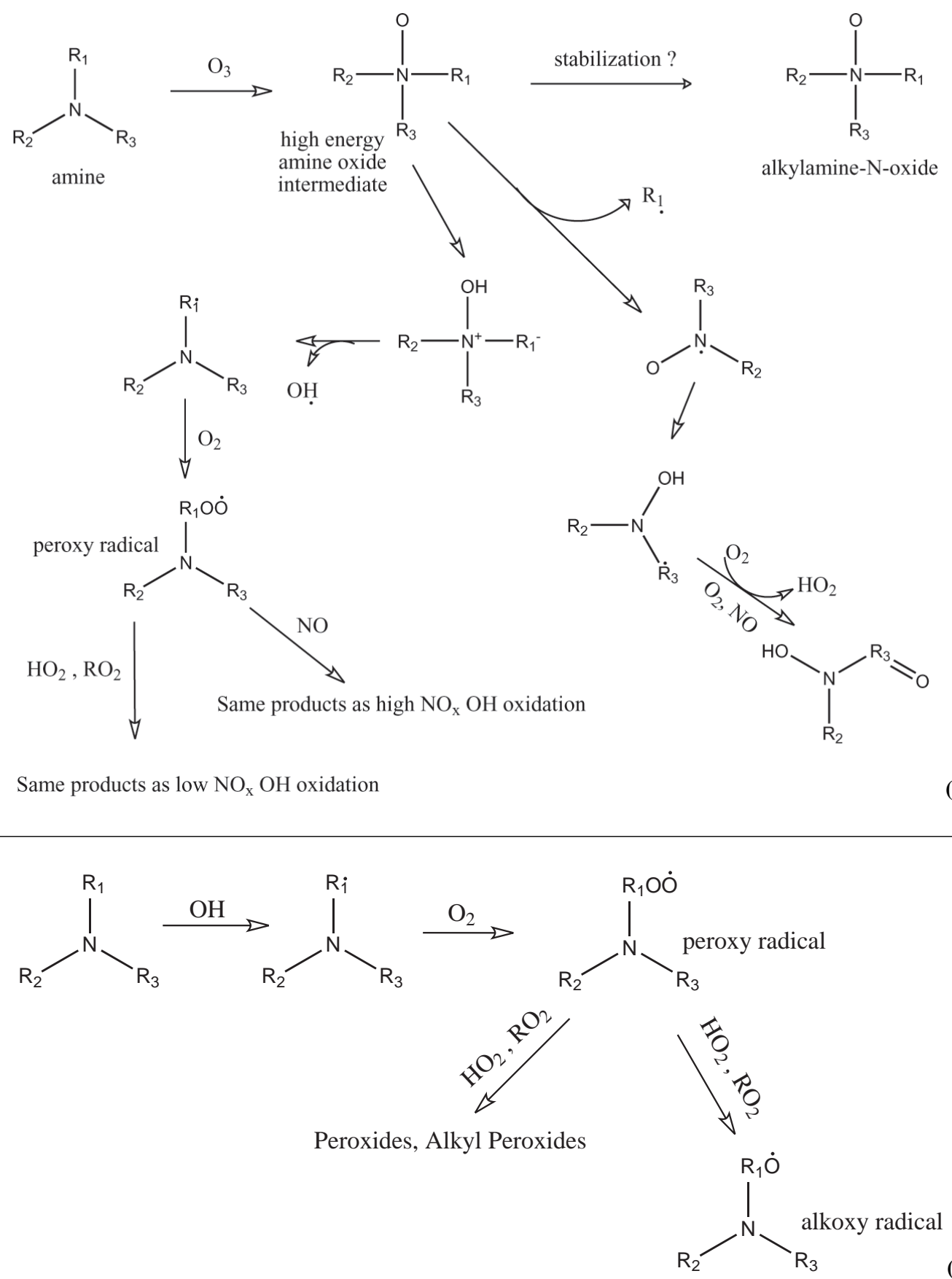

(c)

Fig. 5b+c. Mechanism of amine oxidation by (b) Ozone, in the absence of $\mathrm{NO}_{\mathrm{x}}$ (Tuazon et al., 1994), (c) $\mathrm{OH}$ in the absence of $\mathrm{NO}_{\mathrm{x}}$. A ? indicates an unknown oxidation mechanism to form the product shown.

equilibrium. The composition of the TMAN particles was measured for an additional $30 \mathrm{~min}$ with the cToF-AMS and the PILS-IC before the black lights surrounding the chamber were turned on, initiating photooxidation.

When photooxidation begins, because of the large excess of TMA injected relative to $\mathrm{HNO}_{3}$, much of the nitric acid has been converted into particle-phase nitrate. Assuming negligible wall loss, $\sim 90 \mathrm{ppb}$ of TEA remains in the gas phase at the time the lights are turned on. Upon irradiation, there is a brief spike in $\mathrm{NO}$ from the photolysis of $\mathrm{NO}_{2}$; as the TMA is oxidized by $\mathrm{OH}, \mathrm{RO}_{2}$ radicals are formed that convert the $\mathrm{NO}$ back to $\mathrm{NO}_{2}$, and ozone formation begins. $\mathrm{NO}_{\mathrm{x}}$ gradually decreases throughout the course of the experiment as $\mathrm{NO}_{2}$ is converted to $\mathrm{HNO}_{3}$ by reaction with $\mathrm{OH}$. Particle formation begins within $\sim 10 \mathrm{~min}$ of the start of irradiation. 


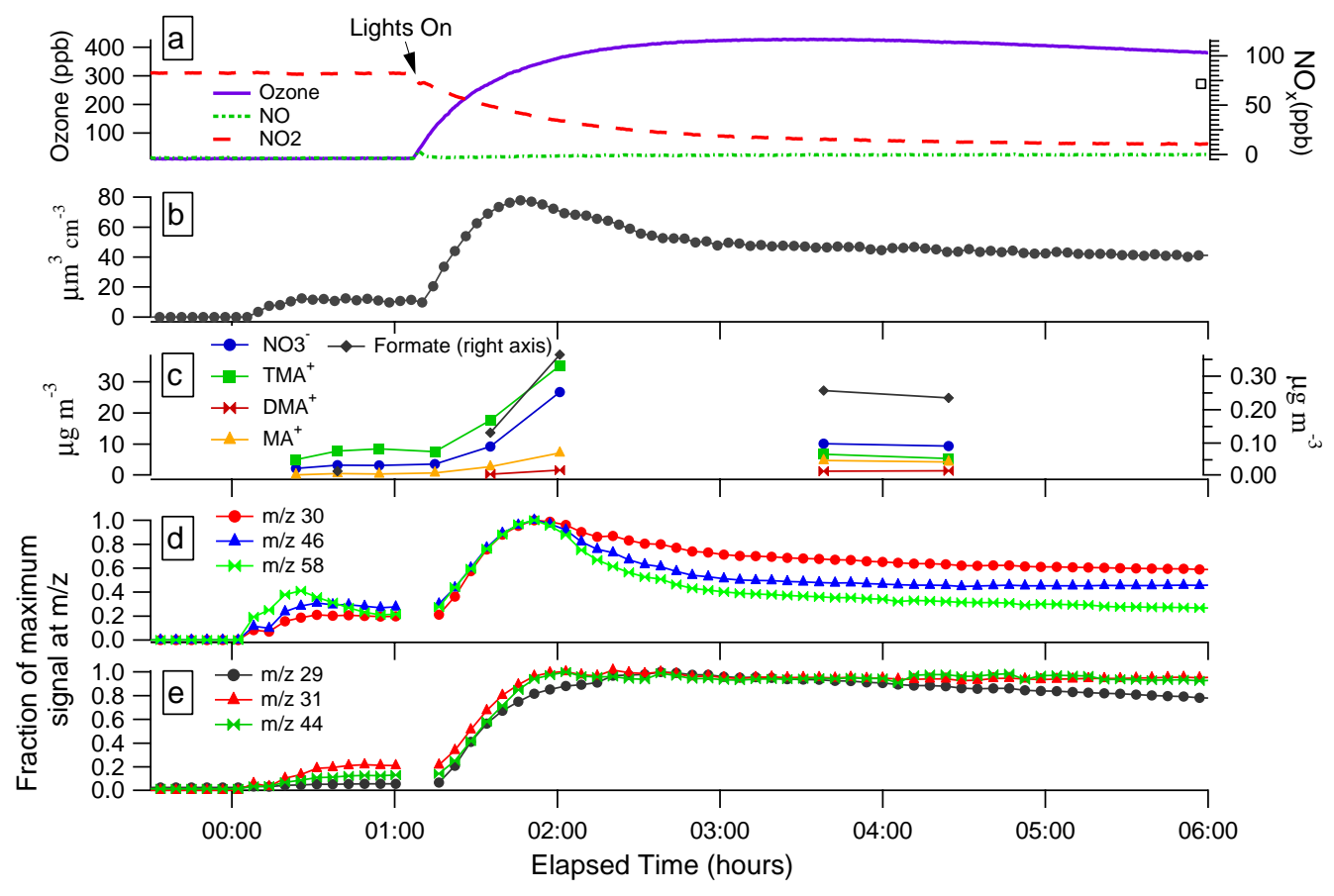

Fig. 6. Photooxidation of trimethylamine (experiment 3 from Table 2). Panel (a) $\mathrm{NO}_{\mathrm{x}}$ and ozone concentrations. Panel (b) Particle volume measured by the DMA. Panel (c) Growth of ionic species measured by the PILS-IC. Panels (d) and (e) Fragment ions from the cToF-AMS. When injected, the TMA reacts with nitric acid in the chamber to form trimethylammonium nitrate. Upon activation of the black lights, there is an initial burst of particle growth followed by a rapid decay in particle mass and volume. The PILS-IC data show that much of the decay is a result of volatilization of the trimethylammonium nitrate salt. The cToF-AMS traces show that while $m / z$ 's corresponding to trimethylammonium nitrate salt fragments $\left(30 \mathrm{NO}^{+}, 46 \mathrm{NO}_{2}{ }^{+}, 58\left(\left(\mathrm{CH}_{3}\right)_{2} \mathrm{NCH}_{2}{ }^{+}\right)\right.$rapidly decrease after the peak in growth, $m / z$ 's corresponding to methylammonium nitrate $\left(31 \mathrm{CH}_{3} \mathrm{NH}_{2}{ }^{+}\right)$and oxidized fragments $\left(29 \mathrm{HCO}^{+}, 44 \mathrm{CO}_{2}{ }^{+}\right)$are level or decrease much more gradually.

Figure 6c-e shows the particle composition as measured by the cToF-AMS and the PILS-IC instruments. The PILS-IC data show that at the peak of particle growth, $62 \mu \mathrm{g} \mathrm{m}^{-3}$ of the particle mass consists of TMAN salt. The volume measured by the DMA is $78 \mu \mathrm{m}^{3} \mathrm{~cm}^{-3}$ at the peak of particle growth. Based on a calculated effective density of (1.3 \pm 0.2$)$, nearly $80 \%$ of the particle mass is composed of the nitrate salt at the peak of particle growth. In addition to the salt present at the start of irradiation, additional salt is formed as TMA reacts with nitric acid formed as $\mathrm{OH}$ reacts with $\mathrm{NO}_{2}$. After the peak of particle growth, both the mass and volume of aerosol drop dramatically. The drop in particle mass can be accounted for almost entirely by the volatilization of TMAN, and after $4.4 \mathrm{~h}$ of reaction TMAN salt accounts for less than $35 \%$ of the particle mass. Volatilization of TMAN is a direct consequence of the gas-particle equilibrium of the nitrate salt; as oxidation proceeds and gas-phase TMA is reacted away (and as nitric acid is lost to the walls of the chamber), the equilibrium for the salt shifts back towards the gas phase. Figure 6d-e shows time traces of signals from the cToF-AMS associated with trimethylammonium $(\mathrm{m} / z 58$ $\left.\left(\mathrm{CH}_{3}\right)_{2} \mathrm{NCH}_{2}^{+}\right)$, methylammonium $\left(m / z 31 \mathrm{CH}_{3} \mathrm{NH}_{2}^{+}\right)$, nitrate $\left(m / z 30 \mathrm{NO}^{+}, m / z 46 \mathrm{NO}_{2}^{+}\right)$and oxidized fragments $\left(m / z 44 \mathrm{CO}_{2}^{+}, m / z 29 \mathrm{CHO}^{+}\right)$. The signals associated with trimethylammonium and nitrate all decrease quickly after the peak of particle growth while those associated with oxidized fragments and methylamine are relatively flat (some show slight decreases associated with the slow loss of particles to the chamber walls). The time trends of these fragments lend support to the hypothesis that TMAN salt is repartitioning to the gas phase while compounds formed from TMA oxidation are condensing.

Over the course of the reaction, both the cToF-AMS and the PILS-IC detected signals consistent with the presence of particle-phase methylammonium. Based on the PILS-IC data, nearly $10 \%$ of the particle mass at the peak of aerosol growth is methylammonium. The most plausible explanation for the detection of this species is that imines formed in the gas phase (see Fig. 5a) partition to the particle phase through either nitrate salt formation or direct condensation. Imines exposed to liquid water readily decompose into an amine and an aldehyde (Fig. 5a). It is possible that this reaction occurs in the particle phase, though it is unclear if sufficient particle-phase water existed to drive this reaction. The experiments are carried out at low RH $(<10 \%)$ but both the TEA and nitric acid were bubbled into the chamber from aqueous 


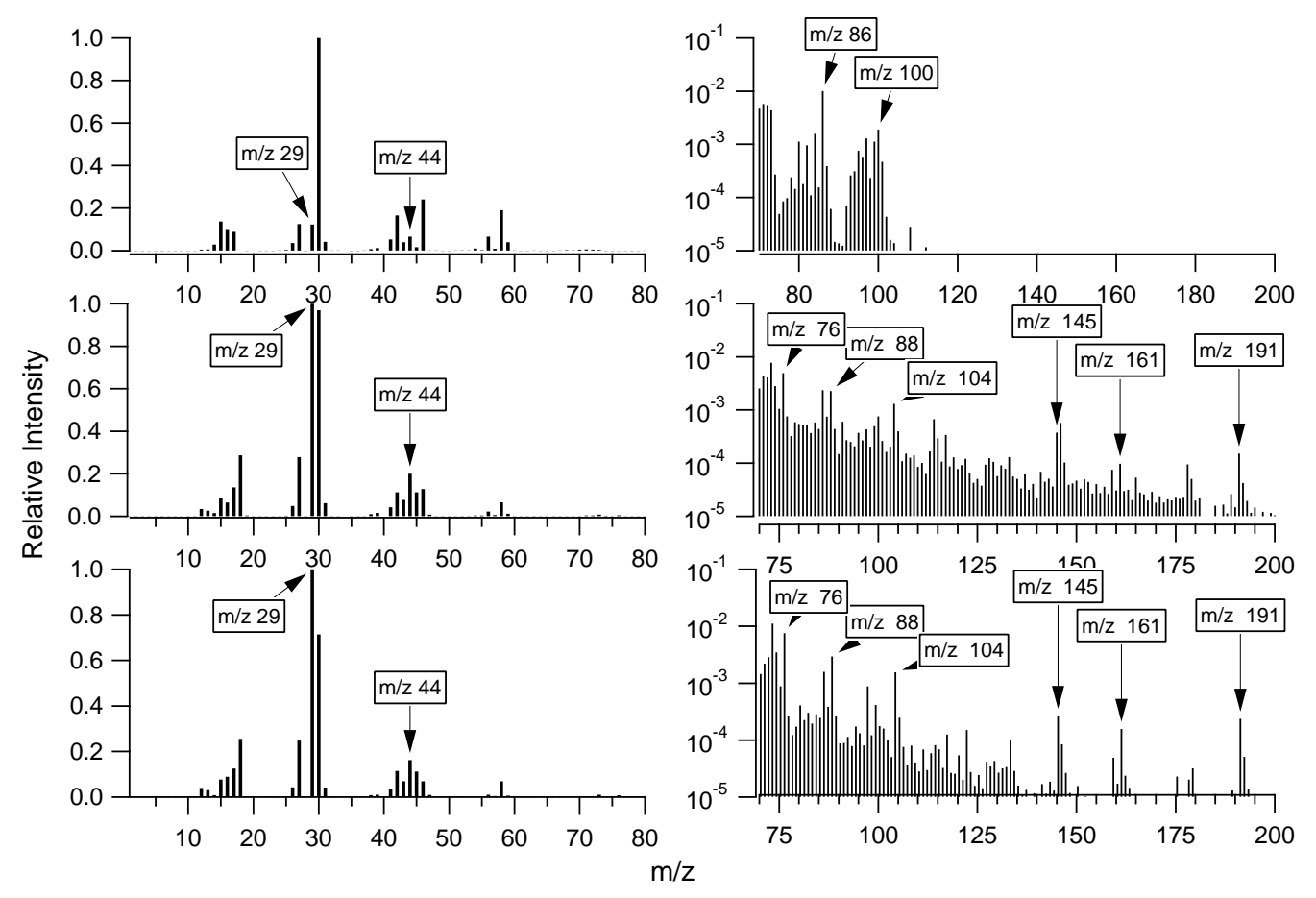

Fig. 7. Aerosol mass spectra from the cToF-AMS during different stages of trimethylamine photooxidation (Fig. 6) and ozonolysis (Fig. 8). The top panel shows trimethylammonium nitrate before oxidation while the middle panel is from the end of the photooxidation experiment ( $8 \mathrm{~h}$ elapsed time). The bottom panel shows the spectra from aerosol formed from TMA after $\sim 3 \mathrm{~h}$ of ozone exposure. The right and left panels show different $\mathrm{m} / \mathrm{z}$ ranges of the same spectra. The major peaks shift during the photooxidation from peaks corresponding to the trimethylammonium nitrate salt to more oxidized peaks $\left(29 \mathrm{HCO}^{+}, 44 \mathrm{CO}_{2}^{+}\right)$. There is also a significant increase in the fraction of higher molecular weight species.

solutions and the efflorescence behavior of aminium nitrate particles is unknown (although if their behavior is similar to that of ammonium nitrate, the particles may retain water at low RH). Independent of the amount of particle water, because the PILS-IC dissolves collected aerosol particles into water droplets, the imines would almost certainly react with water inside of the instrument if this reaction had not already occurred in the chamber. The fact that more methylammonium nitrate is detected by the PILS-IC than dimethylammonium nitrate further supports the imine reaction pathway because this pathway does not lead to dimethylammonium nitrate. The PILS-IC data also show an increase in the abundance of formate, which is a byproduct of hydrolysis of imines. While the cToF-AMS peak at $\mathrm{m} / \mathrm{z} 31$ could be a fragment from oxidized forms of TMA and not from methylammonium, it is improbable that this peak is a fragment from TMAN itself because it does not follow the same time profiles as $m / z 58$ (the dominant peak for TMAN). It is improbable that this peak is a fragment from TMAN itself because it does not follow the same time profiles as $m / z 58$ (the dominant peak for TMAN). The small amounts of dimethylammonium nitrate detected by the PILS-IC could be formed through hydrolysis of amides in the particle phase as shown in Fig. 5a.
Figure 7 shows the spectra from the cToF-AMS during different stages of the same photooxidation experiment discussed above (experiment 3, Table 2). As in Fig. 6, the growing importance of oxidized fragments relative to trimethylammonium nitrate fragments is evident. Of note is the relative prominence of $m / z 88$, which is the expected dominant peak (resulting from alpha-cleavage) of the carboxylic acid of TMA (shown in the bottom of Fig. 5a). Also of note is the increase in abundance of higher molecular weight species which could be the result of particle-phase reactions or multiple oxidations in the gas phase. The gas-phase route seems somewhat implausible for molecular weights above $150\left(\mathrm{RO}_{2}+\mathrm{RO}_{2}=148 \mathrm{amu}\right.$ for TMA) because formation of these high molecular weight compounds would require multiple $\mathrm{RO}_{2}+\mathrm{RO}_{2}$ or $\mathrm{RO}_{2}+\mathrm{HO}_{2}$ reactions.

\subsection{Trimethylamine (TMA) ozonolysis}

During the photooxidation of trimethylamine a large amount of ozone is formed, and, based on reported rate constants (Atkinson et al., 1978; Tuazon et al., 1994), ozone and $\mathrm{OH}$ reactions with TMA are competitive under these conditions. To determine if the products of the ozone reaction form aerosol, we conducted a TMA ozonolysis experiment. 

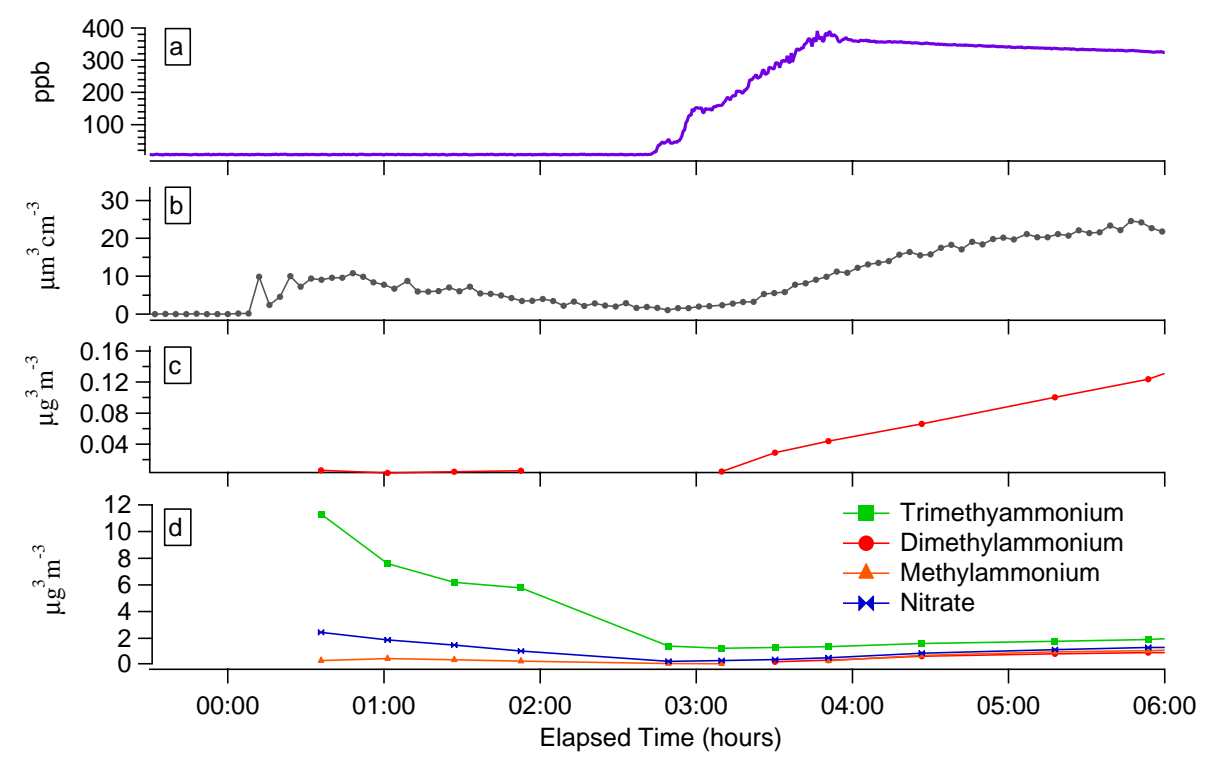

Fig. 8. Ozonolysis of trimethylamine (exp. 4, Table 2). Trimethylamine is injected into a chamber containing $18 \mathrm{ppb}$ of nitric acid at time $=0$. The salt is allowed to decay away before $400 \mathrm{ppb}$ of ozone is injected over $\sim 1 \mathrm{~h}$. Panel (a) Ozone concentration. Panel (b) DMA volume showing significant aerosol growth as the TMA is oxidized. Panel (c) Formate concentration measured by the PILS-IC. Panel (d) Ions measured by the PILS-IC, showing that there is little increase in salt concentrations during the ozonolysis.

Figure 8 shows the time series of the DMA, cToF-AMS, and PILS-IC for this experiment. At time $=0,100 \mathrm{ppb}$ of TMA was added to $16 \mathrm{ppb}$ of $\mathrm{HNO}_{3}$ already in the chamber, forming trimethylammonium nitrate (TMAN). The TMAN salt remained in the chamber for $\sim 3 \mathrm{~h}$ during which time nearly all of it deposited on the chamber walls or volatilized. Oxidation was initiated by adding $200 \mathrm{ppb}$ of ozone to the remaining gas-phase TMA in the system $(\sim 85 \mathrm{ppb}$ assuming negligible wall loss of gas phase TMA and assuming all of the particulate TMAN was lost to the walls). During the ozonolysis, the vast majority $(>90 \%)$ of the aerosol formed was nonionic and accordingly was not detected by the PILS-IC. After $3 \mathrm{~h}$ of ozonolysis, aerosol growth had reached a peak. At this point, nitric acid was added (not shown in Fig. 8) to induce nitrate salt formation of gas-phase products too volatile to condense. The addition of nitric acid led to $9 \mu \mathrm{m}^{3} \mathrm{~cm}^{-3}$ of aerosol growth, which was predominantly TMAN with a small contribution from methylammonium nitrate.

Though a large excess of ozone remained after the peak of aerosol growth, the aerosol formed appeared to be stable towards further oxidation and did not rapidly revolatilize. The mass yield of non-salt aerosol (before additional nitric acid was injected) was $\sim 15 \%$ (assuming $85 \mathrm{ppb}$ as the starting concentration of amine). Interestingly, the yield from the ozonolysis is similar to the $23 \%$ yield of oxidized (non-salt) SOA formed during photooxidation with $\mathrm{NO}_{\mathrm{x}}$.

The bottom panel of Fig. 7 shows a spectrum from the cToF-AMS after three hours of ozone oxidation. The similarity between this spectrum and that in the middle panel of the figure (after photooxidation) is striking, with the one obvious difference being that the nitrate fragments $(\mathrm{m} / \mathrm{z} 30$ and 46) are less prominent because nitrate salts represent a smaller fraction of the particulate mass in the ozonolysis experiment. The similarity of the spectra indicates that ozonolysis generates similar condensable compounds to those from photooxidation. It should be noted that $\mathrm{OH}$ can be created during ozonolyis (see Fig. 5) and some of the compounds formed in ozonolyis could potentially be formed from amine reaction with $\mathrm{OH}$.

\subsection{Methylamine (MA) photooxidation}

In addition to being formed through oxidation and hydrolysis of TMA, methylamine (MA) is itself a major emission from animal husbandry operations. In the study of Schade and Crutzen (1995) methylamine and trimethylamine were the only two aliphatic amines detected near animal husbandry operations. Figure 9 shows the time series for the photooxidation of methylamine (experiment 6, Table 2) using $\mathrm{H}_{2} \mathrm{O}_{2}$ as the $\mathrm{OH}$ precursor. Nitric acid, in the amount of $10 \mathrm{ppb}$, was added before methylamine was injected, and $\mathrm{NO}_{\mathrm{x}}$ was added as $100 \mathrm{ppb}$ of $\mathrm{NO}$, instead of as $\mathrm{NO}_{2}$. Injection of the methylamine caused the nucleation of methylammonium nitrate, which was allowed to equilibrate and mix for approximately two hours before the black lights were turned on $2.5 \mathrm{~h}$ after injection of the amine. When irradiation began, $\mathrm{NO}$ was quickly converted to $\mathrm{NO}_{2}$ through reactions with $\mathrm{RO}_{2}$ and $\mathrm{HO}_{2}$. As $\mathrm{NO}$ was removed, ozone formation began, $\mathrm{NO}_{2}$ started to convert to $\mathrm{HNO}_{3}$, and aerosol formation began. The aerosol volume shows the same behavior as that during 


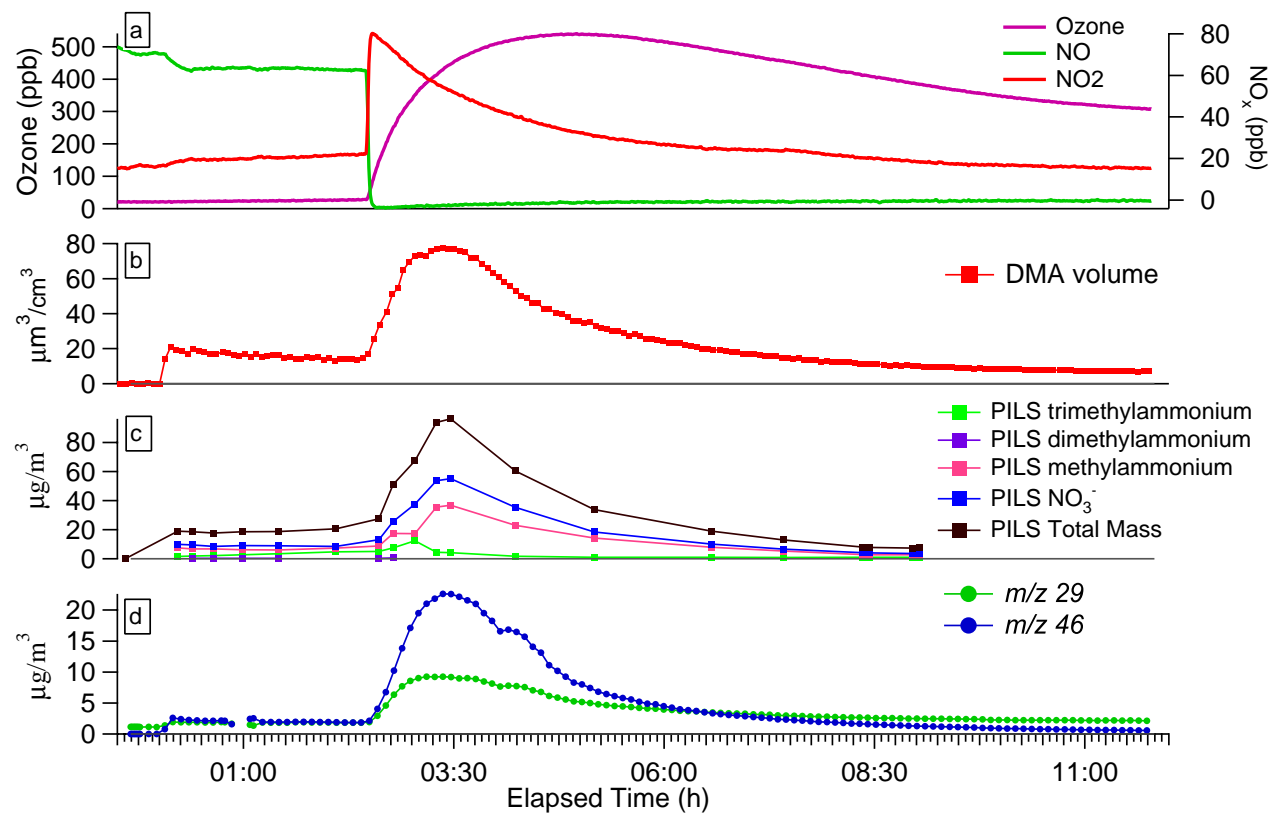

Fig. 9. Methylamine photooxidation (exp. 6, Table 2). Panel (a) Ozone and $\mathrm{NO}_{\mathrm{x}}$ concentrations. Panel (b) Time series for the DMA volume showing rapid decay after the peak of aerosol growth. Panel (c) Time series for the PILS-IC showing that most of the rapid mass decay is due to vaporization of the methylammonium nitrate salt. Panel (d) Fragment ions from the cToF-AMS. Signal from $m / z 29$ which is a mix of oxidized organic fragments $\left(\mathrm{CHO}^{+}\right)$and salt fragments gradually grows more important than signal from from salt alone $\left(m / z 46 \mathrm{NO}_{2}{ }^{+}\right)$.

the TMA photooxidation, growing to a peak as methylammonium nitrate is formed then rapidly decaying as gas-phase methylamine is oxidized. Subtracting the mass of all the ionic species detected by the PILS-IC from the aerosol mass calculated by multiplying the DMA volume by the effective density of $1.1 \pm 0.2$, one finds that nearly $100 \%$ of the aerosol formed at the peak of aerosol growth is methylammonium nitrate. There is a small signal in the PILS-IC from contaminant TMA which decreases as the experiment progresses. In contrast to the TMA photooxidation, there is little aerosol remaining after the rapid decay of the salt; $<1 \mu \mathrm{g} \mathrm{m}^{-3}$ of nonsalt organic aerosol is present in the system after $4 \mathrm{~h}$ of photooxidation relative to more than $20 \mu \mathrm{g} \mathrm{m}^{-3}$ remaining for the TMA with similar starting concentrations of amine. Though the mass of non-salt aerosol formed from the photooxidation was small, Panel (D) of Fig. 9 shows that the relative importance of non-salt organic aerosol increases throughout the experiment. Methanimine, one of the most abundant gasphase products from methylamine photooxidation is known to polymerize on surfaces and may be a source of the nonionic aerosol detected (Schade and Crutzen, 1995).

\subsection{Methylamine (MA) ozonolysis}

Because the vast majority of the aerosol formed during the photooxidation of methylamine is methylammonium nitrate, we performed an ozonolysis experiment to confirm that methylamine is unable to generate significant aerosol mass through oxidative routes. Time series from the ozonolysis have already been shown, though in the context of sulfate salt formation, in Fig. 4. Ammonium sulfate seed was added to the methylamine-ozonolysis system to provide a surface for condensation if the system did not generate enough condensable products to induce nucleation. Ozone, in the amount of $200 \mathrm{ppb}$, was added to the chamber along with $\sim 100 \mathrm{ppb}$ of methylamine. As discussed previously, the methylamine replaced the ammonium from the ammonium sulfate seed, but after this initial phase of growth by displacement, negligible further growth was observed, confirming the result of negligible non-salt organic mass yield observed during the photooxidation.

\subsection{Triethylamine (TEA) photooxidation}

Results from the photooxidation of $500 \mathrm{ppb}$ of triethylamine with $\mathrm{NO}_{\mathrm{x}}$ using hydrogen peroxide as an $\mathrm{OH}$ precursor are shown in Fig. 10. For all TEA photooxidations, independent of $\mathrm{OH}$ source or starting concentration, rapid decay of aerosol mass after the peak growth was not observed. The reason for the observed stability of the salt formed is unclear. It probably indicates that TEAN has a smaller dissociation constant than the other amines studied. It could also indicate that there is interaction between the organic material and the salt lowering the volatility of the TEAN. Finally, it could be the result of salt formation by products of TEA oxidation. During all TEA photooxidations, diethylammonium and ethylammonium were detected by the PILS-IC with diethylammonium being formed at higher 


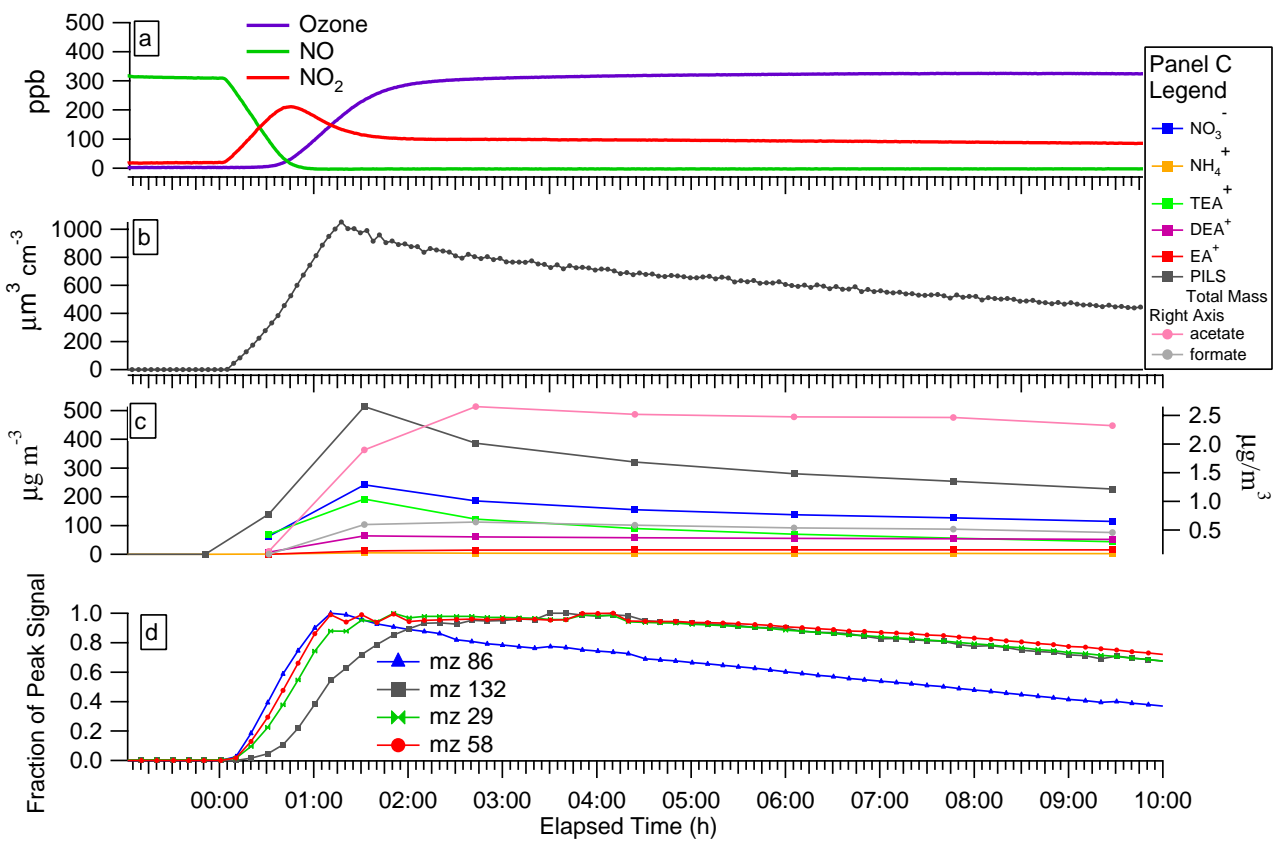

Fig. 10. Photooxidation of $500 \mathrm{ppb}$ triethylamine (TEA) (exp. 9, Table 2). Irradiation is initiated at $\mathrm{t}=0$. Panel (a) Evolution of ozone and $\mathrm{NO}_{\mathrm{x}}$. Panel (b) DMA volume. Panel (c) Time profile of species detected by the PILS-IC showing that diethylammonium and ethylammonium are formed during the photooxidation, with significantly more diethylammonium being formed. Panel (d) Fragments from the cToF-AMS. The most intense fragment of TEA $\left(\mathrm{m} / z 86 \mathrm{~N}\left(\mathrm{CH}_{2} \mathrm{CH}_{3}\right)_{2} \mathrm{CH}_{2}{ }^{+}\right)$grows in first followed by the major peak for DEA $(m / z 58$ $\left.\mathrm{NH}\left(\mathrm{CH}_{2} \mathrm{CH}_{3}\right) \mathrm{CH}_{2}{ }^{+}\right)$and oxidized fragments $\left(\mathrm{m} / z 29 \mathrm{CHO}^{+}\right)$. Higher molecular weight fragments $(\mathrm{m} / z$ 132) grow in more slowly.

concentrations in the particle phase than ethylammonium. Based on our knowledge of the gas-phase oxidation reactions, it seems most plausible that the diethylammonium is formed by the particle-phase hydrolysis of N,N diethylacetamide (the amide shown in Fig. 5a if all R groups are ethyl groups. As mentioned earlier, it is possible that hydrolysis of the amide occurs in the PILS-IC instrument itself rather than in the chamber.) The detection of acetate by the PILSIC during the experiment is consistent with the proposed mechanism of diethylammonium formation from hydrolysis of N,N diethylacetamide. The ethylammonium detected by the PILS-IC could be formed in two ways. First, it could result from aqueous reaction of the imine as shown in Fig. 5a (if all $\mathrm{R}$ groups being ethyl). Second, it could be the result of two successive amide hydrolysis reactions. The detection of higher levels of diethylammonium than ethylammonium contrasts with the results from the oxidation of trimethylamine for which higher levels of methylamine were detected than for dimethylamine. This difference suggests that more aerosol is formed through the imine route for trimethylamine whereas more aerosol is formed through the amide route for triethylamine.

During one photooxidation of TEA (experiment 20), a filter of the aerosol was collected and analyzed by LC/MS with electrospray ionization. All of the mass spectral peaks observed using LC/MS were consistent with the nitrate salt and oxidation products already discussed, except for a peak at $\mathrm{m} / \mathrm{z} 118$ detected in the positive mode. Peaks detected in the positive mode from electrospray ionization are typically $[\mathrm{M}+\mathrm{H}]^{+}$ions, making the molecular weight of the species detected $117 \mathrm{amu}$. This molecular weight is consistent with triethylamine-N-oxide (shown in Figs. 5a and b with $\mathrm{R}=$ ethyl group), a species that was previously detected by Angelino et al. (2001). There is not a significant peak in the spectrum from the cToF-AMS at $m / z 117$ (or $m / z 116$ which would be the expected largest fragment ion peak resulting from the alpha cleavage of a hydrogen from triethylamine-N-oxide); this is not particularly surprising because a high energy oxide of this type would be expected to fragment under electron impact ionization if it had not already thermally fragmented on the vaporizer. The extracted ion chromatogram (EIC) of $\mathrm{m} / z 118$ from the LC/MS system gives three distinct peaks with retention times of $1.38,2.00$, and 2.30 min, indicating the presence of three distinct isomers of this species. The structures of these isomers remain unknown.

\subsection{Triethylamine (TEA) ozonolysis}

Ozonolysis of TEA was conducted using the same procedure as for the ozonolysis of TMA and MA. First, nucleation of triethylammonium nitrate (TEAN) was initiated by adding $100 \mathrm{ppb}$ of TEA to a chamber containing $8 \mathrm{ppb}$ of nitric acid. After allowing the TEAN to equilibrate for $2 \mathrm{~h}$, 


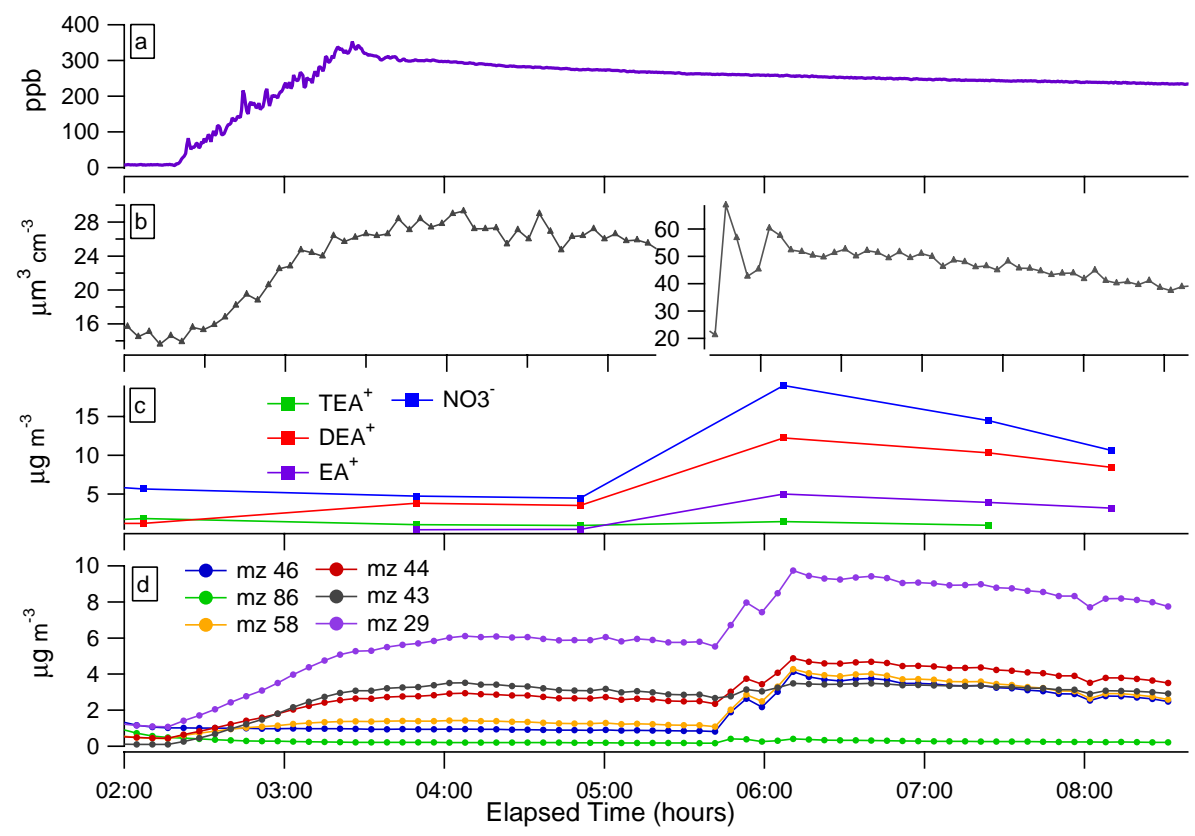

Fig. 11. Ozonolysis of triethylamine (TEA) (exp. 16, Table 2). At $\mathrm{t}=0$ (not shown) $100 \mathrm{ppb}$ of TEA is injected into a chamber containing $8 \mathrm{ppb}$ of nitric acid, nucleating triethylammonium nitrate (TEAN) particles, which are still present when ozone is injected at $\mathrm{t}=2 \mathrm{~h} 12 \mathrm{~min}$. After growth of secondary aerosol formed through ozonolysis had ceased, an additional $8 \mathrm{ppb}$ of nitric acid was injected at $5 \mathrm{~h} 31 \mathrm{~min}$. Panel (a) Time series of ozone mixing ratio Panel (b) Aerosol volume as measured by the DMA (the time axis is coincident with all of the other panels, two y-axes have been used to show more precisely the growth resulting from ozonolysis). Panel (c) Ionic species measured by the PILS-IC showing an increase in DEA throughout the reaction and condensation of EA when additional $\mathrm{HNO}_{3}$ is added Panel (d) Ion fragments detected by the cToF-AMS: $m / z \quad 46 \mathrm{NO}_{2}{ }^{+}, m / z, 86 \mathrm{~N}\left(\mathrm{CH}_{2} \mathrm{CH}_{3}\right)_{2} \mathrm{CH}_{2}{ }^{+}$(largest peak from triethylammonium), $m / z$. 58 $\mathrm{NH}\left(\mathrm{CH}_{2} \mathrm{CH}_{3}\right) \mathrm{CH}_{2}{ }^{+}$(largest peak from Diethylammonium), $m / z 44 \mathrm{CO}_{2}^{+}, m / z 43 \mathrm{C}_{2} \mathrm{H}_{3} \mathrm{O}^{+}, m / z 29 \mathrm{CHO}^{+}$.

$350 \mathrm{ppb}$ of ozone was slowly added to the chamber causing further aerosol growth that peaked, after $\sim 3 \mathrm{~h}$ of ozone exposure, at a maximum of $15 \mu \mathrm{m}^{3} \mathrm{~cm}^{-3}$, or $\sim 18 \mu \mathrm{g}^{3} \mathrm{~m}^{-3}$ (effective density $=1.2 \pm 0.2$ ) of additional growth. The mass yield from ozonolysis is $5 \%$.

During ozonolysis, diethylammonium and ethylammonium were formed as they were during photooxidation, but there was no corresponding growth in the nitrate signal (either on the cToF-AMS or the PILS-IC) indicating that these compounds condensed in the particle phase in a form other than nitrate salts. At the peak of aerosol growth $(3 \mathrm{~h}$ of oxidation), diethylammonium constituted $23 \%$ of the aerosol mass formed after ozone injection and ethylammonium accounted for $3 \%$ of the mass from ozonolysis. After the aerosol growth had peaked, an additional $8 \mathrm{ppb}$ of nitric acid was added causing a further $30 \mu \mathrm{g} \mathrm{m}^{-3}$ of aerosol growth. The aerosol generated by this second addition of nitric acid was a mix of diethylammonium $\left(8.7 \mu \mathrm{g} \mathrm{m}^{-3}\right)$, ethylammonium $\left(4.5 \mu \mathrm{g} \mathrm{m}^{-3}\right)$, triethylammonium $\left(0.5 \mu \mathrm{g} \mathrm{m}^{-3}\right)$, and nitrate $\left(14.5 \mu \mathrm{g} \mathrm{m}^{-3}\right)$. The near perfect ion balance between the positive amine ions and the negative nitrate ions (3\% negative charge imbalance) substantiates that all of the additional growth was in the form of nitrate salts. The negligible increase in triethylammonium mass during the second addition of nitric acid indicates that nearly all of the starting TEA had been oxidized. The final aerosol, composed of nitrate salts and oxidized SOA, did not rapidly decay. The PILS-IC data showed that nitrate decayed 7 percent faster than ethylammonium and 14 percent faster than diethylammonium further supporting the idea that these species are not entirely nitrate salts and that nitrate salts decay more rapidly than SOA formed through oxidation.

\subsection{Diethylamine (DEA) photooxidation}

Figure 12 shows the photooxidation of $100 \mathrm{ppb}$ of diethylamine, conducted in the same manner as the previously discussed photooxidations using hydrogen peroxide as an $\mathrm{OH}$ precursor. Diethylammonium nitrate nucleates upon injection of DEA followed by a burst of aerosol mass when the lights are turned on that quickly decays away. The rapid decay is similar to the behavior of TMA and MA during photooxidation, with DEA being more similar to MA in that nearly all of the aerosol formed is nitrate salt. Experiments using different $\mathrm{OH}$ sources also yielded negligible non-salt aerosol. This is an intriguing result, because by molecular weight alone, DEA would be predicted to form more secondary organic aerosol when oxidized than TMA. Clearly, in this case, the chemical nature of the compound is more 


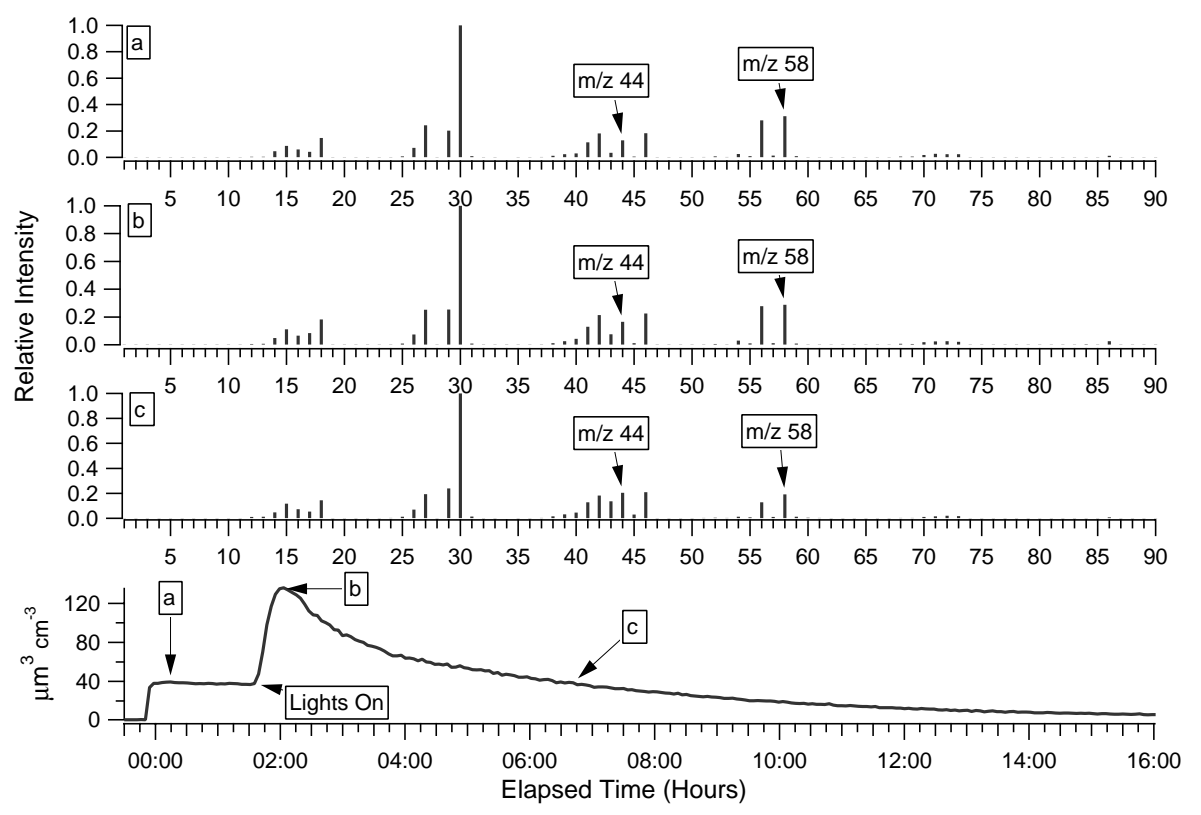

Fig. 12. Photooxidation of diethlyamine (exp. 22, Table 2). The volume trace from the DMA (bottom panel) shows that the aerosol formed decays quickly back to the volume present before the irradiation. The prominent peaks in the cToF-AMS spectra (Panels a-c) show little change throughout the course of the experiment, except for a slight increase in the relative intensity of oxidized peaks at $m / z 44\left(\mathrm{CO}_{2}{ }^{+}\right)$and $m / z 43\left(\mathrm{C}_{2} \mathrm{H}_{3} \mathrm{O}^{+}\right)$. There was also little change in the high $\mathrm{m} / z$ spectra indicating negligible growth of high molecular weight species.

important than molecular weight alone. Though the specific reactions that lead to the difference in yield between TEA and DEA remain unclear, Fig. 5 shows that there are several compounds that can be formed by tertiary amines through the loss of one of the alkyl groups, a reaction pathway that is not available for secondary or primary amines. Though believed to be a minor channel, $\mathrm{OH}$ can also extract a hydrogen atom directly from the nitrogen of primary and secondary amines; it is possible that this reaction pathway leads to more volatile compounds. Because photooxidation yielded no non-salt organic aerosol, an ozonolysis experiment was not conducted for DEA.

\subsection{Ethylamine (EA) photooxidation}

One photooxidation of ethylamine was conducted and yielded negligible non-salt aerosol mass. Though there was contamination from a previous DEA experiment, it is doubtful that this affected the amount of organic aerosol formed. Ethylamine ozonolysis was not pursued because of the negligible non-salt yield during photooxidation.

\subsection{Ethanolamine (MEA) photooxidation and ozonolysis}

Figure 13 shows the photooxidation of ethanolamine. Aerosol growth follows the same pattern as for the other amines with the majority of the initial growth being composed of nitrate salts that repartition back to the gas phase as the amine reacts away. Non-salt organic aerosol forms
( $\sim 2 \%$ mass yield), but the yield is small as it is for the other non-tertiary amines studied. The cToF-AMS data show that oxidized fragments $\left(\mathrm{m} / \mathrm{z} 44, \mathrm{CO}_{2}^{+}\right)$grow in more gradually and decay less than fragments associated with ethanolammonium nitrate $\left(m / z \quad 46 \mathrm{NO}_{2}^{+}\right.$and $m / z \quad 30 \mathrm{NO}^{+}$and the major ion fragment from ethanolammonium itself). The PILSIC shows growth of diethylammonium though this is probably a result of contamination because it is unclear how ethanolamine could react to form diethylammonium. The yield from ozonolysis of ethanolamine was small ( $\sim 3 \%)$, as expected from the small yield observed during photooxidation.

\subsection{Photooxidation in the absence of $\mathrm{NO}_{\mathrm{x}}$}

$\mathrm{NO}_{\mathrm{x}}$-free photooxidation experiments were conducted for both TEA and DEA. In both cases, negligible mass from nitrate salts was detected by the PILS-IC. Following the trends of the high $\mathrm{NO}_{\mathrm{x}}$ photooxidation and ozonolysis results, $500 \mathrm{ppb}$ of TEA formed $260 \mu \mathrm{g} \mathrm{m}^{-3}$ of aerosol (mass yield of $\sim 12 \%$ ) while $500 \mathrm{ppb}$ DEA formed less than $2 \mu \mathrm{g}$ $\mathrm{m}^{-3}$ (mass yield of $\sim 0.1 \%$ ). The cToF-AMS mass spectrum from the $\mathrm{NO}_{\mathrm{x}}$-free photooxidation of TEA is shown in Fig. 14. No dramatic changes in the mass spectrum occur during the course of the experiment. 


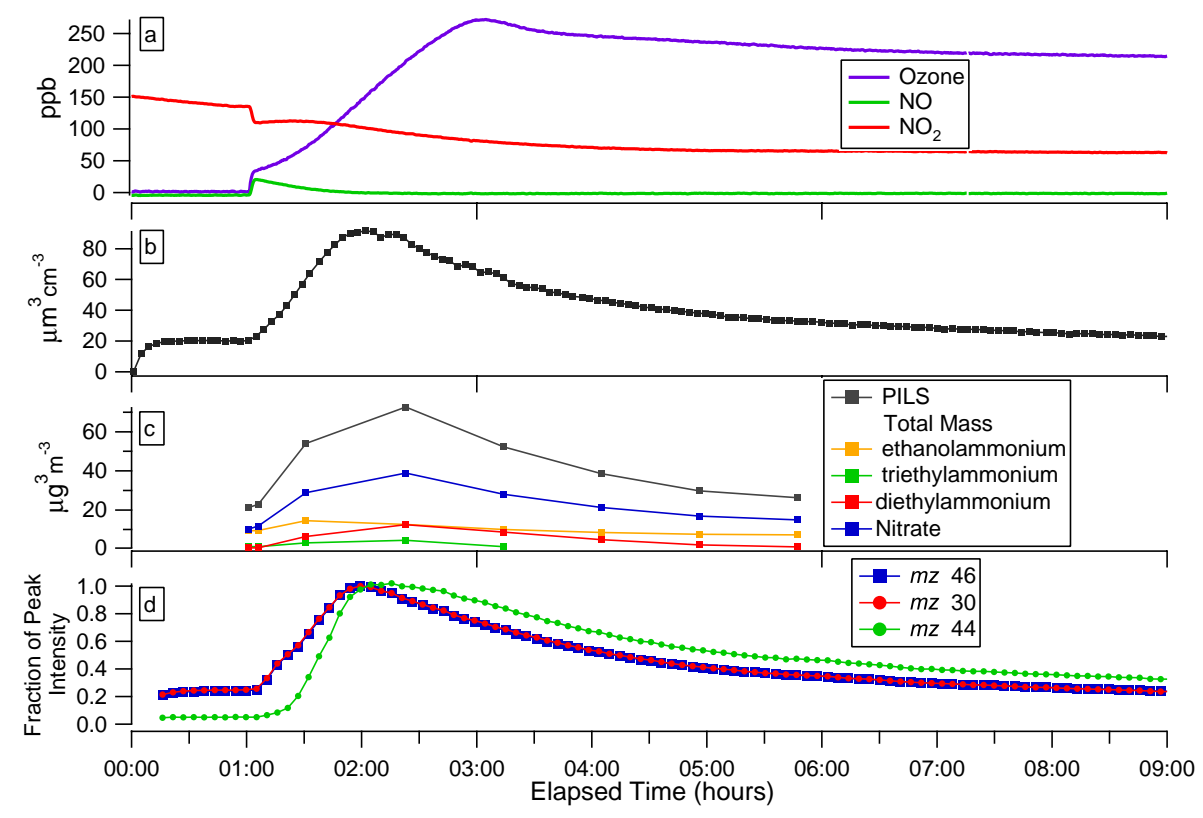

Fig. 13. Photooxidation of $100 \mathrm{ppb}$ of ethanolamine (MEA) (exp. 29, Table 2). Ethanolamine is injected at $t=0$ forming ethanolammonium nitrate. Panel (a) Evolution of ozone and $\mathrm{NO}_{\mathrm{x}}$ mixing ratios. Panel (b) DMA volume. Panel (c) PILS-IC data. Panel (d) Fragments from the cToF-AMS. Oxidized fragment ions $\left(\mathrm{m} / z, 44 \mathrm{CO}_{2}{ }^{+}\right)$grow in slowly and decay less quickly than nitrate fragment ions $\left(\mathrm{m} / z+6 \mathrm{NO}_{2}{ }^{+}\right.$and $\left.m / z 30 \mathrm{NO}^{+}\right)$or ethanolammonium fragment ions $(\mathrm{m} / z, 30$ is the base peak for ethanolammonium in the cToF-AMS).

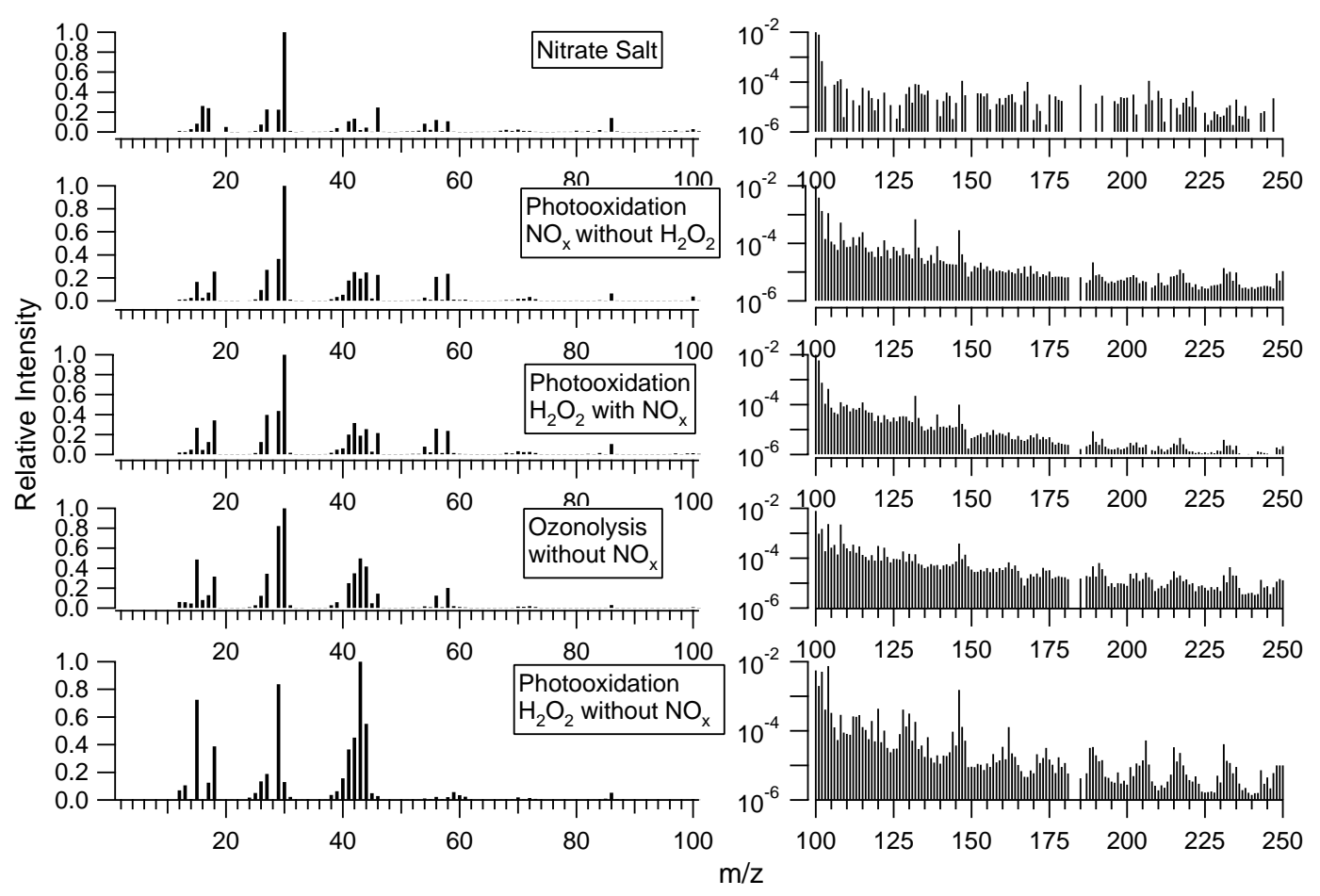

Fig. 14. cToF-AMS spectra (normalized to the largest peak) of aerosol generated from TEA oxidation under various conditions. In all cases, except for hydrogen peroxide without $\mathrm{NO}_{\mathrm{x}}$, the nitrate salt was intentionally formed by mixing TEA with nitric acid in the chamber before the start of oxidation. All spectra were collected after the peak of aerosol growth had been reached. 


\subsection{Effect of oxidation conditions on particle chemistry}

Figure 14 shows cToF-AMS spectra from particles formed by oxidation of TEA using four different systems: (1) photooxidation with $\mathrm{NO}_{\mathrm{x}}$ alone, (2) photooxidation with $\mathrm{NO}_{\mathrm{x}}$ using $\mathrm{H}_{2} \mathrm{O}_{2}$ as an $\mathrm{OH}$ precursor, (3) ozonolysis in the absence of $\mathrm{NO}_{\mathrm{x}}$, and (4) photooxidation in the absence of $\mathrm{NO}_{\mathrm{x}}$ using $\mathrm{H}_{2} \mathrm{O}_{2}$ as an $\mathrm{OH}$ precursor. Because the cToFAMS uses electron impact ionization, differences in the peak height ratios can be used to assess chemical similarity between the systems even though the spectra are highly fragmented. Aerosol formed in the two different photooxidation systems containing $\mathrm{NO}_{\mathrm{x}}$ have similar spectra with large peaks corresponding to fragments from the nitrate salt mixed with oxidized fragments $\left(m / z 29 \mathrm{HCO}^{+}, m / z 44 \mathrm{COO}^{+}\right.$, $m / z 43 \mathrm{C}_{2} \mathrm{H}_{3} \mathrm{O}^{+}$, etc.). The spectrum of aerosol generated by photooxidation (using hydrogen peroxide as an $\mathrm{OH}$ precursor) in the absence of $\mathrm{NO}_{\mathrm{x}}$ is the most distinct from all other spectra, with dramatically different peak height ratios ( $m / z 43$ is the most intense signal) and more high molecular weight fragments than the other systems. The ozone spectrum shows characteristics of both the high and low $\mathrm{NO}_{\mathrm{x}}$ spectra including a relatively large, yet not dominant, $\mathrm{m} / \mathrm{z}$ 43 peak.

The spectra from different oxidation systems show that in addition to affecting how much nitrate salt is formed, oxidant $\left(\mathrm{OH}, \mathrm{O}_{3}\right)$ and $\mathrm{NO}_{\mathrm{x}}$ levels also affect the chemical composition of the oxidized aerosol. At the same time, the similarities between the spectra from high $\mathrm{NO}_{\mathrm{x}}$ photooxidation systems with and without $\mathrm{H}_{2} \mathrm{O}_{2}$ indicate that similar species condense independent of the $\mathrm{OH}$ source. All of the amines studied formed aerosol with similar spectra during photooxidation whether or not hydrogen peroxide was used as an $\mathrm{OH}$ precursor.

\subsection{Effective density shifts}

During the photooxidations of TEA and TMA the effective density of the aerosol continually increased as non-salt organic mass condensed. Figure 1 shows the increase observed during the photooxidation of TEA. The effective density of the aerosol formed during ozonolysis was higher than that of the salt for both TEA and TMA. Additionally, TEA formed aerosol with a higher effective density than TEAN when photooxidized in the absence of $\mathrm{NO}_{\mathrm{x}}$. The increases in effective densities observed in particles with a higher fraction of non-salt mass indicates that either: (1) the non-salt aerosol is more dense; or (2) the salt aerosol is either non-spherical or has void volumes, and the condensation of organic aerosol onto the salt alters these physical characteristics. In either case, it is evident that the physical morphology of the particles depends on the ratio of non-salt to salt mass.

\section{Implications}

Amines can undergo similar acid-base reactions as ammonia to form atmospheric nitrate and sulfate salts when in the presence of $\mathrm{HNO}_{3}$ or $\mathrm{H}_{2} \mathrm{SO}_{4}$. Whether amines, in fact, will form such aminium salts depends not only on the concentration of the amine and the acid, but also on the concentration of ammonia which competes for acidic molecules. Thermodynamic calculations using entropies estimated from quantum mechanics and molecular dynamics indicate that diethylammonium nitrate will be able to form when ammonia mixing ratios are greater than those of diethylamine. Triethylamine was shown experimentally to have a dissociation equilibrium constant similar to that of ammonia. Ethylammonium nitrate and trimethylammonium nitrate are predicted to be unable to form unless their mixing ratios are near to or greater than that of ammonia. We note that thermodynamic parameters for the aminium salts have large uncertainties that preclude us from making conclusions regarding the formation, in the presence of ammonia, of the other aminium salts studied.

Gas-phase amines are subject to atmospheric oxidation by the $\mathrm{OH}$ radical and ozone, leading to secondary organic aerosol formation. If nitric or sulfuric acid is present during the oxidation, aminium salts of the parent amine can form simultaneously with the SOA resulting from oxidation. The products of amine oxidation can also be basic and form additional aminium salts. Aminium salts will most often form in source-rich areas. As the parent amine is reacted away or as the air mass undergoes dilution, aminium salts can be expected to repartition back to the gas phase. SOA resulting from amine oxidation appears to be more stable in the particle phase than the aminium salts.

Table 4 gives the non-salt organic aerosol yields for all of the amines studied under a number of different oxidative conditions. While the yields shown are only applicable to the amine:oxidant and oxidant: $\mathrm{NO}_{\mathrm{x}}$ ratios of the particular experiments, we can draw the general conclusion that the tertiary amines (TMA and TEA) are able to form significant yields of non-salt SOA while the primary and secondary amines studied are not. Ethanolamine showed a small growth during ozonolysis which may be an indication that adding functional groups to the amines increases their organic (nonsalt) aerosol yield.

\section{Appendix A}

\section{Thermodynamic data for amine systems}

Table A1 lists available thermodynamic data for common amine systems. Multiple heats of formation values of alkylammonium nitrates are listed to highlight their uncertainty. Data on entropy and heat capacities for alkylammonium nitrates, with the exception of ammonium nitrate, do not appear to be available. 
Table A1. Thermodynamic data for various amine nitrate systems. Amines and nitric acid are in the gas phase and nitrates are solid.

\begin{tabular}{llll}
\hline Substance & $\Delta H_{f}^{\circ}(\mathrm{kJ} / \mathrm{mol})$ & $S^{\circ}(\mathrm{J} / \mathrm{mol} \mathrm{K})$ & $\mathrm{C}_{P}(\mathrm{~J} / \mathrm{mol} \mathrm{K})$ \\
\hline ammonia & $-45.90^{\mathrm{d}}$ & $192.77^{\mathrm{e}}$ & $35.65^{d}$ \\
methylamine & $-23.0^{\mathrm{f}}$ & $243^{\mathrm{g}}$ & $53^{\mathrm{g}}$ \\
dimethylamine & $-18.5^{\mathrm{f}}$ & $273^{\mathrm{g}}$ & $70.8^{\mathrm{g}}$ \\
trimethylamine & $-23.7^{\mathrm{f}}$ & $287^{\mathrm{g}}$ & $91.8^{\mathrm{g}}$ \\
ethylamine & $-47.5^{\mathrm{f}}$ & $285^{\mathrm{g}}$ & $72.7^{\mathrm{g}}$ \\
diethylamine & $-72.6^{\mathrm{f}}$ & $352^{\mathrm{g}}$ & $115.7^{\mathrm{g}}$ \\
triethylamine & $-92.4^{\mathrm{f}}$ & $405^{\mathrm{g}}$ & $160.9^{\mathrm{g}}$ \\
ethanolamine & $-210.2^{\mathrm{j}}$ & $321^{\mathrm{j}}$ & $85.3^{\mathrm{j}}$ \\
& & & $140^{\mathrm{c}}$ \\
ammonium nitrate & $-365.61^{\mathrm{a}}$ & $146.44^{\mathrm{b}} \mid 141.56^{*}$ & $194.7^{*}$ \\
methylammonium nitrate & $-337^{\mathrm{h}} \mid-354.4^{\mathrm{k}}$ & $229.9^{*}$ & \\
dimethylammonium nitrate & $-331^{\mathrm{h}} \mid-350.2^{\mathrm{k}}$ & $243.5^{*}$ & $206^{\mathrm{i}}$ \\
trimethylammonium nitrate & $-306^{\mathrm{h}} \mid-343.9^{\mathrm{k}}$ & $237.2^{*}$ & \\
ethylammonium nitrate & $-364^{\mathrm{h}} \mid-366.9^{\mathrm{k}}$ & $299.9^{*}$ & $350.3^{*}$ \\
diethylammonium nitrate & $-413^{\mathrm{h}} \mid-418.8^{\mathrm{k}}$ & & \\
triethylammonium nitrate & $-407^{\mathrm{h}} \mid-447.7^{\mathrm{k}}$ & $266.39^{\mathrm{d}}$ & \\
ethanolammonium nitrate & $-576^{\mathrm{h}} \mid-577^{\mathrm{k}}$ & & $53.31^{\mathrm{d}}$ \\
nitric acid & $-134.31^{\mathrm{d}}$ & & \\
\hline
\end{tabular}

*values estimated from quantum mechanics/molecular dynamics

${ }^{\mathrm{a}}$ Cox et al. (1979), ${ }^{\mathrm{b}}$ Eichenauer and Liebscher (1965), ${ }^{\mathrm{c}}$ Wagman et al. (1968), ${ }^{\mathrm{d}}$ Chase et al. (1998), ${ }^{\mathrm{e}}$ Haar (1968), ${ }^{\mathrm{f}} \mathrm{Schmitz}$ et al. (2001), gerry et al. (1997), ${ }^{\mathrm{h}}$ Cottrell and Gill (1951), ${ }^{\mathrm{i}}$ Allen et al. (1985), ${ }^{\mathrm{j}}$ Yaws (2003), ${ }^{\mathrm{k}}$ Wagman et al. (1982)

One approach is to extract the entropy information from atomistic classical and quantum simulation. Lin et al. (2003) developed a 2-phase thermodynamic approach for calculating the thermodynamic properties of complex systems from single molecular dynamics simulation trajectories. In general the Fourier transform of the velocity autocorrelation function, obtained from a molecular dynamics trajectory is used to obtain the vibrational density of states, which is then used to calculate the thermodynamic properties by applying quantum statistics assuming each vibrational mode is a harmonic oscillator. This approach is quite accurate for solids, but leads to significant errors for liquids. Lin et al. (2003) extend this approach to fluids by applying the 2-phase model in which the density of states of the fluid systems are partitioned into gas and solid like components. However, for aminium nitrates that are solids in ambient conditions, the harmonic approximation is sufficiently accurate for entropy estimation.

Of the alkylammonium nitrates, crystal structures were only found for ammonium nitrate (Herrmann et al., 1994) and methylammonium nitrate (Mylrajan et al., 1985). For the compounds with experimental crystal structures, the periodic quantum mechanical (QM) Mulliken charge distribution were determined by the SeqQuest program (Feibelman, 1987; Verdozzi et al., 2002). For the compounds lacking experimental crystal structure, the solid structures were es- timated by modifying the methylammonium nitrate crystal. For instance, methyl groups were replaced by ethyl groups in order to create the ethylammonium nitrate crystal structure. The QM charges were obtained using Density Functional Theory (DFT), B3LYP (Becke, 1993) functions as implemented in the Jaguar program (Jaguar, 2005) using basis sets aug-cc-pvtz (Kendall et al., 1992). Solid structures were built using this method for di and trimethylammonium nitrate, mono, di and triethylammonium nitrate in CERIUS2 (Cerius2, 1999). Molecular dynamic (MD) simulation at constant pressure, temperature and number of particles (NPT) were performed to equilibrate these solid structures. NVT simulations were then carried out for these experimental crystals or equilibrated solids for a total of $50 \mathrm{ps}$. Long-range interactions are included using the Ewald sum method and the Nose-Hoover thermostat. Using the MD trajectories, the density of states can be obtained, and the entropies can then be determined from quantum statistics (Lin et al., 2003).

The QM entropy is expected to be quite accurate for crystalline systems. Indeed, the QM entropy agrees rather well with the experimental values for ammonium nitrate (141.56 J/molK vs. $146.44 \mathrm{~J} / \mathrm{molK})$. Unfortunately, experimental entropy is available only for ammonium nitrate so further comparison cannot be done. Since crystal structure was also available for methylammonium nitrate, we expect 
its QM entropy to be reasonably accurate. For other aminium nitrates, the accuracy of the calculated entropies remains undetermined although we observed a sensible correlation between the "flexibility" of the alkyl groups and the entropies.

Acknowledgements. This work was supported by the Electric Power Research Institute.

Edited by: A. Laaksonen

\section{References}

Allan, J. D, Jimenez, J. L, Williams, P. I, Alfarra, M. R, Bower, K. N, Jayne, J. T, Coe, H., and Worsnop, D. R: Quantitative sampling using an Aerodyne aerosol mass spectrometer: 1. Techniques of data interpretation and error analysis, J. Geophys. Res., 108(D3), 4090, doi:10.1029/2002JD002358, 2003.

Allen, M., Evans, D. F., and Lumry, R.: Thermodynamic properties of the ethylammonium nitrate + water-system - partial molar volumes, heat-capacities, and expansivities, J. Solution. Chem., 14(8), 549-560, 1985.

Angelino, S., Suess, D. T., and Prather, K. A.: Formation of aerosol particles from reactions of secondary and tertiary alkylamines: Characterization by aerosol time-of-flight mass spectrometry, Environ. Sci. Technol., 35(15), 3130-3138, 2001.

Atkinson, R., Perry, R. A., and Pitts, J. N.: Rate constants for reactions of $\mathrm{OH}$ radical with $(\mathrm{CH} 3) 2 \mathrm{NH},(\mathrm{CH} 3) 3 \mathrm{~N}$, and $\mathrm{C} 2 \mathrm{H} 5 \mathrm{NH} 2$ over temperature range 298-426 degrees K, J. Chem. Phys., 68(4), 1850-1853, 1978.

Bahreini, R., Keywood, M. D., Ng, N. L., Varutbangkul, V., Gao, S., Flagan, R. C., Seinfeld, J. H., Worsnop, D. R., and Jimenez, J. L.: Measurements of secondary organic aerosol from oxidation of cycloalkenes, terpenes, and m-xylene using an Aerodyne aerosol mass spectrometer, Environ. Sci. Technol., 39(15), 5674-5688, 2005.

Becke, A. D.: Density-functional thermochemistry III. The role of exact exchange, J. Chem. Phys., 98(7), 5648-5652, 1993.

Beddows, D. C. S., Donovan, R. J., Harrison, R. M., Heal, M. R., Kinnersley, R. P., King, M. D., Nicholson, D. H., and Thompson, K. C.: Correlations in the chemical composition of rural background atmospheric aerosol in the UK determined in real time using time-of-flight mass spectrometry, J. Environ. Monit., 6(2), 124-133, 2004.

Cerius2, v. 4.0, Accelrys, San Diego, CA, 1999.

Chase, M. W.: NIST-JANAF themochemical tables, fourth edition, J. Phys. Chem. Ref. Data, Monograph 9, 1343-1290, 1998.

Cocker, D. R., Flagan, R. C., and Seinfeld, J. H.: State-of-the-art chamber facility for studying atmospheric aerosol chemistry, Environ. Sci. Technol., 35(12), 2594-2601, 2001.

Cottrell, T. L. and Gill, J. E.: The preparation and heats of combustion of some amine nitrates, J. Chem. Soc., (Jul), 1798-1800, 1951.

Cox, J. D., Harrop, D., and Head, A. J.: Standard enthalpy of formation of ammonium-nitrate and of the nitrate ion, J. Chem. Thermodyn., 11(8), 811-814, 1979.

DeCarlo, P. F., Slowik, J. G., Worsnop, D. R., Davidovits, P., and Jimenez, J. L.: Particle morphology and density characterization by combined mobility and aerodynamic diameter measurements. Part 1: Theory, Aerosol Sci. Technol., 38(12), 1185-1205, 2004.
Drewnick, F., Jayne, J. T., Canagaratna, M., Worsnop, D. R., and Demerjian, K. L.: Measurement of ambient aerosol composition during the PMTACS-NY 2001 using an aerosol mass spectrometer. Part II: Chemically speciated mass distributions, Aerosol Sci. Technol., 38, 104-117, 2004a.

Drewnick, F., Schwab, J. J., Jayne, J. T., Canagaratna, M., Worsnop, D. R., and Demerjian, K. L.: Measurement of ambient aerosol composition during the PMTACS-NY 2001 using an aerosol mass spectrometer. Part I: Mass concentrations, Aerosol Sci. Technol., 38, 92-103, 2004b.

Eichenau, W. and Liebsche, D.: Die molwarme des ammoniumnitrats zwischen 11 und 280 degrees K, Zeitschrift fúr Naturforschung Part a-Astrophysik Physik und Physikalische Chemie, A 20(1), 160, 1965.

Feibelman, P. J.: Force and total-energy calculations for a spatially compact adsorbate on an extended, metallic crystal surface, Phys. Rev. B, 35(6), 2626-2646, 1987.

Finlayson-Pitts, B. J. and Pitts, J. N. J.: Atmospheric chemistry : Fundamentals and experimental techniques, Wiley, New York, 1986.

Haar, L.: Thermodynamic properties of ammonia as an ideal gas, J. Res. Nbs. A. Phys. Ch., A 72(2), 207, 1968.

Hamoir, J., Nemmar, A., Halloy, D., Wirth, D., Vincke, G., Vanderplasschen, A., Nemery, B., and Gustin, P.: Effect of polystyrene particles on lung microvascular permeability in isolated perfused rabbit lungs: Role of size and surface properties, Toxicol. Appl. Pharmacol., 190(3), 278-285, 2003.

Herrmann, M., Engel, W., Schneider, J., and Goebel, H.: Rietveld refinement of the phase of $\mathrm{NH} 4 \mathrm{NO} 3$ measured in-situ under different diffraction geometries, Materials Science Forum, 166, 489-494, 1994.

Huffman, J. A., Jayne, J. T., Drewnick, F., Aiken, A. C., Onasch, T., Worsnop, D. R., and Jimenez, J. L.: Design, modeling, optimization, and experimental tests of a particle beam width probe for the Aerodyne aerosol mass spectrometer, Aerosol Sci. Technol., 39(12), 1143-1163, 2005.

Jaguar, v. 6.5, Schrodinger, LLC, New York, NY, 2005.

Jayne, J. T., Leard, D. C., Zhang, X. F., Davidovits, P., Smith, K. A., Kolb, C. E., and Worsnop, D. R.: Development of an aerosol mass spectrometer for size and composition analysis of submicron particles, Aerosol Sci. Technol., 33(1-2), 49-70, 2000.

Kendall, R. A., Dunning Jr., T. H., and Harrison, R. J.: Electron affinities of the first-row atom revisited. Systematic basis sets and wave functions, J. Chem. Phys., 96(9), 6796-6806, 1992.

Keywood, M. D., Varutbangkul, V., Bahreini, R., Flagan, R. C., and Seinfeld, J. H.: Secondary organic aerosol formation from the ozonolysis of cycloalkenes and related compounds, Environ. Sci. Technol., 38(15), 4157-4164, 2004.

Kroll, J. H., Ng, N. L., Murphy, S. M., Flagan, R. C., and Seinfeld, J. H.: Secondary organic aerosol formation from isoprene photooxidation, Environ. Sci. Technol., 40(6), 1869-1877, 2006.

Lin, S.-T., Blanco, M., and Goddard III, W. A.: The twophase model for calculating thermodynamic properties of liquids from molecular dynamics: Validation for the phase diagram of Lennard-Jones fluids, J. Chem. Phys., 119(22), 11792-11 805, 2003.

Mace, K. A., Artaxo, P., and Duce, R. A.: Water-soluble organic nitrogen in Amazon basin aerosols during the dry (biomass burning) and wet seasons, J. Geophys. Res., 108(D16), 4512, 
doi:10.1029/2003JD003557, 2003.

Makela, J. M., Yli-Koivisto, S., Hiltunen, V., Seidl, W., Swietlicki, E., Teinila, K., Sillanpaa, M., Koponen, I. K., Paatero, J., Rosman, K., and Hameri, K.: Chemical composition of aerosol during particle formation events in boreal forest, Tellus B, 53(4), 380-393, 2001.

McGregor, K. G. and Anastasio, C.: Chemistry of fog waters in California's central valley: 2. Photochemical transformations of amino acids and alkyl amines, Atmos. Environ., 35(6), 10911104, 2001.

Mozurkewich, M.: The dissociation-constant of ammoniumnitrate and its dependence on temperature, relative-humidity and particle-size, Atmos. Environ. A-Gen., 27(2), 261-270, 1993.

Murphy, D. M. and Thomson, D. S.: Chemical composition of single aerosol particles at idaho hill: Positive ion measurements, J. Geophys. Res., 102(D5), 6341-6352, 1997.

Mylrajan, M., Srinivasan, T. K. K., and Sreenivasamurthy, G.: Crystal structure of monomethylammonium nitrate, J. Cryst. Spectrosc., 15(5), 493-500, 1985.

Neff, J. C., Holland, E. A., Dentener, F. J., McDowell, W. H., and Russell, K. M.: The origin, composition and rates of organic nitrogen deposition: A missing piece of the nitrogen cycle?, Biogeochemistry, 57(1), 99-136, 2002.

Nemmar, A., Hoylaerts, M. F., Hoet, P. H. M., Dinsdale, D., Smith, T., Xu, H. Y., Vermylen, J., Nemery, B., and Nemery, B.: Ultrafine particles affect experimental thrombosis in an in vivo hamster model, Am. J. Resp. Crit. Care., 166(7), 998-1004, 2002.

Ngwabie, N. M. and Hintz, T.: Mxing ratio measurements and flux estimates of volatile organic compounds (voc) from a cowshed with conventional manure treatment indicate significant emmissions to the atmosphere, Geograph. Res. Abstr., 7(01175), 2005.

Perry, R. H., Green, D. W., and Maloney, J. O.: Perry's chemical engineers' handbook, McGraw-Hill, New York, 1997.

Pitts, J. N., Grosjean, D., Vancauwenberghe, K., Schmid, J. P., and Fitz, D. R.: Photo-oxidation of aliphatic-amines under simulated atmospheric conditions - formation of nitrosamines, nitramines, amides, and photo-chemical oxidant, Environ. Sci. Technol., 12(8), 946-953, 1978.

Rabaud, N. E., Ebeler, S. E., Ashbaugh, L. L., and Flocchini, R. G.: Characterization and quantification of odorous and non-odorous volatile organic compounds near a commercial dairy in California, Atmos. Environ., 37(7), 933-940, 2003.

Schade, G. W. and Crutzen, P. J.: Emission of aliphatic-amines from animal husbandry and their reactions - potential source of $\mathrm{N} 2 \mathrm{O}$ and HCN, J. Atmos. Chem., 22(3), 319-346, 1995.

Schmitz, L. R., Chen, K. H., Labanowski, J., and Allinger, N. L.: Heats of formation of organic molecules calculated by density functional theory. III - amines, J. Phys. Org. Chem., 14(2), 9096, 2001.

Seinfeld, J. H. and Pankow, J. F.: Organic atmospheric particulate material, Annu. Rev. Phys. Chem., 54, 121-140, 2003.
Simoneit, B. R. T., Rushdi, A. I., Bin Abas, M. R., and Didyk, B. M.: Alkyl amides and nitriles as novel tracers for biomass burning, Environ. Sci. Technol., 37(1), 16-21, 2003.

Sorooshian, A., Brechtel, F. J., Ma, Y. L., Weber, R. J., Corless, A., Flagan, R. C., and Seinfeld, J. H.: Modeling and characterization of a particle-into-liquid sampler (pils), Aerosol Sci. Technol., 40(6), 396-409, 2006.

Stein, S. E.: Mass spectra by NIST mass spec data center, NIST chemistry webbook, NIST standard reference database number 69, Eds. Linstrom PJ, Mallard WG, National Institute of Standards and Technology, Gaithersburg MD, (http://webbook.nist. gov), 2005.

Stelson, A. W. and Seinfeld, J. H.: Relative-humidity and temperature-dependence of the ammonium-nitrate dissociationconstant, Atmos. Environ., 16(5), 983-992, 1982.

Surratt, J. D., Murphy, S. M., Kroll, J. H., Ng, N. L., Hildebrandt, L., Sorooshian, A., Szmigielski, R., Vermeylen, R., Maenhaut, W., Claeys, M., Flagan, R. C., and Seinfeld, J. H.: Chemical composition of secondary organic aerosol formed from the photooxidation of isoprene, J. Phys. Chem. A, 110(31), 9665-9690, 2006.

Tan, P. V., Evans, G. J., Tsai, J., Owega, S., Fila, M. S., and Malpica, O.: On-line analysis of urban particulate matter focusing on elevated wintertime aerosol concentrations, Environ. Sci. Technol., 36(16), 3512-3518, 2002.

Tuazon, E. C., Atkinson, R., Aschmann, S. M., and Arey, J.: Kinetics and products of the gas-phase reactions of $\mathrm{O}_{3}$ with amines and related-compounds, Res. Chem. Intermed., 20(3-5), 303320, 1994.

Verdozzi, C., Schultz, P. A., Wu, R., Edwards, A. H., and Kioussis, N.: Layer intermixing during metal/metal oxide adsorption: Ti/sapphire(0001), Phys. Rev. B, 66, 125 408, 2002.

Wagman, D. D., Evans, W. H., Parker, V. B., Halow, I., Bailey, S. M., and Schumm, R. H.: Selected values of chemical thermodynamic properties; tables for the first thirty-four elements in the standard order of arrangement, NBS Technical Note, 270(3), 1968.

Wagman, D. D., Evans, W. H., Parker, V. B., Schumm, R. H., Halow, I., Bailey, S. M., Churney, K. L., and Nuttall, R. L.: The nbs tables of chemical thermodynamic properties - selected values for inorganic and C-1 and C-2 organic-substances in si units, J. Phys. Chem. Ref. Data, 11(2), 91-110, 1982.

Weber, R. J., Orsini, D., Daun, Y., Lee, Y. N., Klotz, P. J., and Brechtel, F.: A particle-into-liquid collector for rapid measurement of aerosol bulk chemical composition, Aerosol Sci. Technol., 35(3), 718-727, 2001.

Yaws, C. L.: Yaws' handbook of thermodynamic and physical properties of chemical compounds, Knovel, 2003.

Zhang, Q. and Anastasio, C.: Free and combined amino compounds in atmospheric fine particles (pm2.5) and fog waters from northern California, Atmos. Environ., 37(16), 2247-2258, 2003. 